\title{
Complement Targets Newborn Retinal Ganglion Cells for Phagocytic Elimination by Microglia
}

\author{
Sarah R. Anderson, ${ }^{1,2}$ Jianmin Zhang, ${ }^{1}$ Michael R. Steele, ${ }^{1}$ Cesar 0. Romero, ${ }^{1}$ Amanda G. Kautzman, ${ }^{3}$ \\ Dorothy P. Schafer, ${ }^{3}$ and Monica L. Vetter ${ }^{1}$ \\ ${ }^{1}$ Department of Neurobiology and Anatomy, University of Utah, Salt Lake City, Utah 84112, ${ }^{2}$ Interdepartmental Program in Neuroscience, University of \\ Utah, Salt Lake City, Utah 84112, and ${ }^{3}$ Department of Neurobiology, University of Massachusetts Medical School, Worcester, Massachusetts 01655
}

Microglia play important roles in shaping the developing CNS, and at early stages they have been proposed to regulate progenitor proliferation, differentiation, and neuronal survival. However, these studies reveal contradictory outcomes, highlighting the complexity of these cell-cell interactions. Here, we investigate microglia function during embryonic mouse retina development, where only microglia, progenitors, and neurons are present. In both sexes, we determine that microglia primarily interact with retinal neurons and find that depletion of microglia via conditional KO of the Csf1 receptor results in increased density of retinal ganglion cells (RGCs). Pharmacological inhibition of microglia also results in an increase in RGCs, with no effect on retinal progenitor proliferation, RGC genesis, or apoptosis. We show that microglia in the embryonic retina are enriched for phagocytic markers and observe engulfment of nonapoptotic Brn3-labeled RGCs. We investigate the molecular pathways that can mediate cell engulfment by microglia and find selective downregulation of complement pathway components with microglia inhibition, and further show that C1q protein marks a subset of RGCs in the embryonic retina. KO of complement receptor 3 (CR3; Itgam), which is only expressed by microglia, results in increased RGC density, similar to what we observed after depletion or inhibition of microglia. Thus, our data suggest that microglia regulate neuron elimination in the embryonic mouse retina by complement-mediated phagocytosis of non-apoptotic newborn RGCs.

Key words: complement; microglia; phagocytosis; retina; retinal ganglion cell

Significance Statement

Microglia are emerging as active and important participants in regulating neuron number in development, during adult neurogenesis, and following stem cell therapies. However, their role in these contexts and the mechanisms involved are not fully defined. Using a well-characterized in vivo system, we provide evidence that microglia regulate neuronal elimination by complementmediated engulfment of nonapoptotic neurons. This work provides a significant advancement of the field by defining in vivo molecular mechanisms for microglia-mediated cell elimination. Our data add to a growing body of evidence that microglia are essential for proper nervous system development. In addition, we elucidate microglia function in the developing retina, which may shed light on microglia involvement in the context of retinal injury and disease.

\section{Introduction}

Microglia, the resident innate immune cells of the CNS, shape the developing brain: from regulating the survival of neurons to refining circuits (Nayak et al., 2014; Li and Barres, 2018). Microglia

Received July 20, 2018; revised Nov. 14, 2018; accepted Dec. 24, 2018.

Author contributions: S.R.A. wrote the first draft of the paper; A.G.K., D.P.S., and M.L.V. edited the paper. S.R.A. and M.L.V. designed research; S.R.A., J.Z., M.R.S., and C.O.R. performed research; A.G.K. and D.P.S. contributed unpublished reagents/analytic tools; S.R.A. and M.L.V. analyzed data; S.R.A. wrote the paper.

This work was supported by National Eye Institute R21 EY025082 to M.L.V. and F31 EY025967 to S.R.A., and by National Institute of Mental Health R01 MH113743 to D.P.S. We thank Kathryn Moore, Alejandra Bosco, and Jacki Roberts for providing experimental and conceptual input.

The authors declare no competing financial interests.

Correspondence should be addressed to Monica L. Vetter at monica.vetter@neuro.utah.edu.

https://doi.org/10.1523/JNEUROSCl.1854-18.2018

Copyright $\odot 2019$ the authors $\quad 0270-6474 / 19 / 392025-16 \$ 15.00 / 0$ derive from erythromyeloid precursors in the yolk sac and migrate to the brain and retina at early embryonic stages (Ginhoux et al., 2013). Microglia impact the generation and survival of neurons in vitro, during development, and in adult neurogenic zones (Ekdahl et al., 2009; Sato, 2015). However, microglia can have varying effects on proliferation, differentiation, and neuronal survival; and consequently, the mechanisms by which microglia regulate neurogenesis in vivo are not fully understood.

Microglia maintain homeostasis by clearing dead or dying cells as well as directly regulating death via secretion of cytokines or reactive oxygen species (Bilimoria and Stevens, 2015). Furthermore, growing evidence suggests that microglia can execute stressed but viable cells by phagocytosis, a process called phagoptosis (Brown and Neher, 2014; Vilalta and Brown, 2018). While 
phagoptosis has primarily been characterized in vitro, there is evidence that microglia engulf viable neural progenitors in the developing cortex (Cunningham et al., 2013) and nonapoptotic neurons in contexts of injury or disease (Neher et al., 2013; Zhao et al., 2015; Luo et al., 2016; Alawieh et al., 2018). Whether microglia regulate neuronal survival by phagoptosis in the developing CNS is unknown.

Multiple cell surface cues, or "eat-me signals," stimulate microglial phagocytosis (Ravichandran, 2010; Fourgeaud et al., 2016). The complement cascade is a highly conserved signaling pathway important for innate immunity; allowing immune cells to attack membranes or phagocytose invaders (Ricklin et al., 2010). In the CNS, C1q, an initiation component of the complement pathway, tags neuronal synapses for microglial phagocytosis both in development and disease, including pruning of retinal ganglion cell (RGC) synapses for activity-dependent refinement during postnatal periods (Stevens et al., 2007; Schafer et al., 2012; Stephan et al., 2012; Hong et al., 2016). At present, the molecular signals driving phagoptosis in vivo are largely undetermined, and complement has not been implicated in the phagocytosis of entire neurons in development.

In the retina, complex intrinsic and extrinsic processes regulate the production of seven major groups of retinal cells (Bassett and Wallace, 2012). Like other CNS regions, a substantial number of retinal neurons will be eliminated, a process presumed to be driven by apoptosis (Francisco-Morcillo et al., 2014). RGCs are the earliest-born retinal neurons and undergo the largest reduction in density (Perry et al., 1983; Farah, 2006), which is important for retinal function (Péquignot et al., 2003; Chen et al., 2013). Shortly after birth, a large wave of RGC apoptotic death occurs (Péquignot et al., 2003), but a less-studied, embryonic wave of RGC loss has been observed in monkey, cat, chick, rat, and mouse (Péquignot et al., 2003; Farah, 2006). However, it is currently unclear what is driving this embryonic wave of RGC loss because there is minimal apoptosis in the mouse RGC layer at this time.

The embryonic retina allows for unambiguous assessment of microglial influence on neurogenesis and/or neuronal survival because only microglia, retinal progenitors, and newborn neurons are present. Here, we find that microglia preferentially reside adjacent and interact with neurons. By genetic depletion and pharmacological inhibition of microglia, we demonstrate that microglia normally limit RGC density and provide evidence that this is via phagocytic elimination of nonapoptotic newborn cells. We find that complement proteins are highly expressed in the developing retina and are selectively regulated by inhibition of microglia. Finally, loss of complement receptor 3 (CR3), which is only expressed on microglia, results in increased RGC number. Consequently, we provide evidence for a previously unknown mechanism of RGC elimination and suggest a new role for complement in the phagocytosis of entire, nonapoptotic neurons.

\section{Materials and Methods}

Animals and procedures. All animals were treated within the guidelines of the University of Utah Institutional Animal Care and Use Committee, and all experiments were Institutional Animal Care and Use Committeeapproved. C57B6/2J and B6.Csf1r ${ }^{\text {floxed }}$ (021212) mice were purchased from The Jackson Laboratory. The B6.CX3CR $1^{\mathrm{gfp} /+}$ mice (Jung et al., 2000) were a gift from Richard Lang with permission from Steffen Jung. B6.Cx3cr1cre ${ }^{\text {ERT2 }}$ mice (Yona et al., 2013) were a gift from Steffen Jung. B6.Rosa ${ }^{\text {Tdtomato }}$ mice (Madisen et al., 2010) were a gift from Mario Capecchi. Postnatal CR3 KO and littermate control tissue was a gift from Dorothy Schafer (Coxon et al., 1996). Mice were housed in an Association for Assessment and Accreditation of Laboratory Animal Care- accredited animal facility with $12 \mathrm{~h} \mathrm{light} / 12 \mathrm{~h}$ dark cycles and ad libitum access to food and water. Timed matings were used to determine embryonic stages, and both sexes were used for all experiments. The morning a plug was detected was considered embryonic day 0.5. Minocycline (120 $\mathrm{mg} / \mathrm{kg}$ ) or the same volume of vehicle, $5 \%$ sucrose in PBS, was administered once a day by oral gavage to pregnant dams from embryonic day (e) $12.5-15.5$ or e12.5-e13.5. Tamoxifen was administered to pregnant dams by oral gavage on e9.5, e11.5, and e13.5 at 2, 3, and $3 \mathrm{mg}$, respectively; 45 $\mu \mathrm{g} / \mathrm{g}$ BW of $10 \mu \mathrm{g} / \mu \mathrm{l}$ stock BrdU was injected intraperitoneally $24 \mathrm{~h}$ before death; $4 \mu \mathrm{l} / \mathrm{g}$ BW of $5 \mathrm{~mm}$ stock 5-ethynyl-2-deoxyuridine (EdU) was injected intraperitoneally $48 \mathrm{~h}$ before death. Animals of either sex used for experiments were euthanized by isoflurane asphyxiation followed by cervical dislocation.

Tissue processing. Following death, retinas were dissected in ice-cold $0.1 \mathrm{~m}$ PBS. Whole heads were fixed in $4 \%$ PFA for $45 \mathrm{~min}$ to an hour. Heads were washed 3 times for $15 \mathrm{~min}$ in PBS and underwent 12-16 h consecutive treatments with $15 \%$ and $30 \%$ sucrose in PBS at $4^{\circ} \mathrm{C}$. Heads were then embedded in OCT compound (Tissue-Tek), stored at $-80^{\circ} \mathrm{C}$, and sectioned at $16 \mu \mathrm{m}$ thickness. For retinal whole mounts, eyes were removed from the head and retinas were carefully dissected from the rest of the eye (cornea, lens, retinal pigment epithelium, hyaloid vasculature, vitreous, ciliary body) in ice-cold PBS. Whole neural retinas were washed in PBS for 10-20 min and then fixed in 4\% PFA for 15-30 min at room temperature with rocking.

Immunohistochemistry. Frozen sections were placed in ice-cold PBS for $10 \mathrm{~min}$, blocked for $1 \mathrm{~h}$ at room temperature $(0.2 \%$ Triton-X, $10 \%$ BSA, $10 \%$ normal donkey serum in $0.01 \mathrm{~m}$ PBS), then incubated in primary antibody overnight at $4{ }^{\circ} \mathrm{C}$ in $(0.2 \%$ Triton-X, $5 \%$ BSA in $0.01 \mathrm{M}$ PBS). The following day, sections were washed $3 \times$ with PBS and incubated in secondary antibodies (5\% BSA in PBS) for $2 \mathrm{~h}$ at room temperature, washed, and mounted with Vectashield mounting medium with DAPI (H-1200, Vector Laboratories). For whole-mount immunostaining, retinas were incubated in primary antibody at $4^{\circ} \mathrm{C}$ for $3 \mathrm{~d}$. An extra incubation in $4 \mathrm{M} \mathrm{HCl}$ for $2 \mathrm{~h}$ and wash with a sodium borate buffer was used for BrdU detection before primary antibody incubation. EdU was detected per the Click-iT Plus Kit instructions (C10640, Thermo Fisher Scientific). Primary antibodies used are as follows: goat Brn3 (1:50, Santa Cruz Biotechnology sc-6026), rabbit phospho-histone H3 (pH3) (1:500, Millipore 06-570), rabbit cleaved caspase-3 (CC3, 1:500, BD Biosciences 559565), mouse Rxr $\gamma$ (1:250, Santa Cruz Biotechnology sc-365252), mouse Brn3a (1:50, EMD Millipore MAB1585), rabbit calbindin (1: 2000, EMD Millipore PC253L), goat GFP (1:2000, Abcam ab5450), rabbit Ibal (1:1000, Wako 019-19741), mouse BrdU (1:500, Thermo Fisher Scientific B35128), mouse Cd68 (1:300,Bio-Rad MCA1957), rabbit C1q (11500, Abcam ab182451), and rat Cd11b (1:50, BD Biosciences 563890). Secondary antibodies were produced in donkey against goat, mouse, and rabbit IgG and conjugated to AlexaFluor-488, $-555,-568$, or -647 (Thermo Fisher Scientific).

Confocal microscopy and image analysis. Confocal images were acquired on an inverted Nikon A1R Confocal Microscope. For retinal cross sections, 36 multipoint images were acquired (on average) at $20 \times$ objective with a $3 \times$ digital zoom to obtain a $0.2 \mu \mathrm{m}$ pixel resolution. Multipoints were stitched with a $10 \%$ overlap. Stacks through the $Z$ plane at 0.8 $\mu \mathrm{m}$ steps spanning the entire thickness were max projected $(\sim 16 \mu \mathrm{m})$. Images of retinal whole mounts were on average 144 multipoint images of $\sim 30 \mu \mathrm{m}$ thickness. Image acquisition settings were consistent across ages and genotypes. All analysis was performed manually and blinded using Nikon Elements software. For microglia distribution, every fourth section throughout the retina was analyzed. For all RGC counts (Brn3, $\mathrm{BrdU}$, and EdU), the dorsal central regions (300 $\mu \mathrm{m}$ long, $\sim 0.04 \mathrm{~mm}^{2}$ ) of 5 or 6 central sections were analyzed manually and averaged per retina. Only one retina per animal was analyzed unless otherwise specified. RGC density was calculated along $300 \mu \mathrm{m}$ of central retina for P0-depleted and CR3 WT/KO animals. Microglial density for P0 CR3 WT and KOs was calculated by Ibal counts of the central retina (300 $\mu \mathrm{m}$ long, $\sim 0.05 \mathrm{~mm}^{2}$ area). Microglia density and apoptosis analysis at e13.5 and e16.5 were done on entire cross sections of 5 or 6 central sections per animal. For 3D reconstruction of microglia-RGC interactions, IMARIS software (Bitplane) was used. In brief, high-resolution confocal images ( $20 \times$ objec- 
tive, $8 \times$ digital zoom $)$ through $Z(0.16 \mu \mathrm{m}$ steps $)$ were uploaded into IMARIS to create $3 \mathrm{D}$ renderings. $\mathrm{N}>5$ animals were imaged.

Whole-retina $q R T$-PCR. After death, retinas were carefully dissected in RNase-free conditions using ice-cold RNase-free PBS, removing all nonneural eye tissue (ciliary body, pigmented epithelium, vitreous including hyaloid vasculature at embryonic stages). Promptly, retinas were mechanically dissociated by careful trituration using a sterile $1 \mathrm{ml}$ syringe and 26-gauge needle in RLT buffer. Samples were frozen at $-80^{\circ} \mathrm{C}$ until extraction. RNA was extracted using an RNeasy Micro Kit (QIAGEN, 74004). The concentration and purity of the RNA were measured by a spectrophotometer (NanoDrop ND-1000). First strand cDNA synthesis was performed using the SuperScript III First Strand cDNA synthesis kit (Invitrogen,11752). Quantitative real-time PCR (qRT-PCR) was performed using SYBR Select Master mix and run on the 7900 HT Fast Real-Time PCR system with QuantStudio 12K Flex software (Applied Biosystems) at the University of Utah Genomics Core. Relative quantification was determined by $\Delta \Delta \mathrm{C}_{\mathrm{t}}$ using the QuantStudio Software. Genes of interest were normalized to $\beta$ actin. Primers were designed using Primer-BLAST software. Forward and reverse primer sequences in the $5^{\prime}$ to $3^{\prime}$ orientation are as follows: $\beta$ actin, TGAGAGGGAAATCGTG CGTG, TCGTTGCCAATAGTGATGACCTG; $I b a 1$, CCTGATTGGA GGTGGATGTCAC, GGCTCACGACTGTTTCTTTTTTCC; Cx3cr1, AA AAACACTGGATTTCAGGGGC, CAACCAACACAGGAACAGGGAG; Mertk, CGCTCTGGAGTGGAGGCAC, AAACGCAACAGGAGGTAG GAG; Cd68, GGACACTTCGGGCCATGTTT, CTTACACAGTGGAC TGGGGC; $C 1 q b$, ATGGATGCGTAATCACGGGG, GTCTGGGTTT CAGGCAGTCAAG; C3, TCTGACCTCTGGGGAGAAAAGC, TGGG ACAACCATAAACCACCATAG; $C d 11 b$, TGTGGACTCTCATGCCT CCT, TGGTCATCTCTGAAGCCGTG; $C c r 2$, GGAGCCATACCTGTAA ATGCCA, GCCGTGGATGAACTGAGGTA; VNR, CGTCCTCCAG GATGTTTCTCC, GCTTTGACCTCACAGAGGC; mfges, GTGACTTT GGACACACAGCG, AGAACAACGGGAGGCTAGGT; Tyrobp, GGACC CGGAAACAACACATTG, GATCCCAGAGAGGGCTTGTT; and LRP, GTGTCCAACTGCACAGCAAG, GCAGACGTGAATGTCGCAAT.

Statistical methods. All data were analyzed using Prism 7 (GraphPad) software. Unless stated, an unpaired two-tailed Student's $t$ test was performed to determine statistical significance. If the two samples had unequal variances determined by an $F$ test, we applied the Welch's correction. Two-way ANOVA was used to determine statistical significance among groups with multiple independent variables (see Figs. 1E, $2 F$ ) followed by a post hoc Sidak's multiple-comparisons test. For qPCR analyses, an unpaired Student's $t$ test was performed on the $\delta \mathrm{C}_{\mathrm{t}}$ values. Three litters of e20.5 depleted and P0 CR3 KOs were analyzed. Therefore, Brn3 densities were normalized to littermate controls, and a one-sample $t$ test was performed to account for any potential age differences across litters. Data are presented as the mean; error bars indicate the SEM. qPCR graphs represent fold change; error bars indicate the SEM of $\delta \mathrm{C}_{\mathrm{t}}$ values. We used a $95 \%$ CI. A $p$ value of $<0.05$ was set for rejecting the null hypothesis.

\section{Results \\ Microglia primarily associate with neurons in the developing retina}

Microglia are present as early as embryonic day (e) 11.5 in the mouse retina, shortly after the onset of retinal neurogenesis, shown by immunostaining of activation marker F4/80 (Santos et al., 2008). To obtain a more detailed understanding of microglia distribution during embryonic retinal neurogenesis, we performed Ibal immunostaining on cryosections from the Cx $3 \mathrm{cr} 1$ GFP knockin mouse line (Jung et al., 2000). CX3CR1 (fractalkine receptor), and Iba1, a calcium binding protein, are expressed in microglia and other leukocytes, including circulating monocytes and macrophages (Jung et al., 2000). Retinal microglia were identified as $\mathrm{GFP}^{+} \mathrm{Ibal}^{+}$cells within the retinal parenchyma, distinguishable from $\mathrm{GFP}^{+} \mathrm{Ibal}^{+}$macrophage populations outside of the retina, including vitreal macrophages (Fig. $1 \mathrm{~A}$, yellow arrowheads). We confirmed that these cells within the retina selectively express the microglia-specific marker P2RY12 and not the monocyte marker CCR2 (data not shown). At e12.5, e16.5, and postnatal day (P0), Ibal colocalized with GFP, but Ibal levels were more variable (Fig. $1 A-C$ ). The density of microglia appeared highest at e12.5, consistent with previous work (Santos et al., 2008), and was dynamic throughout development. Using wholeretina $\mathrm{qRT}-\mathrm{PCR}$, we found that, relative to adult (P60), Cx3cr1 and $I b a 1$ gene expression was highest at e12.5, decreased during mid-embryonic stages, and increased again at $\mathrm{P} 0$, consistent with the densities of microglia observed by immunostaining (Fig. 1D) ( $n \geq 3$ each). The dramatic expansion of the retina during the embryonic period results in reduced density of microglia, although microglia numbers also continue to increase (data not shown).

The embryonic retina consists of dividing progenitors and neurons, both of which can be influenced by microglia in other contexts (for review, see Li and Barres, 2018), so we sought to determine with which cell populations microglia may be associating. Before e17.5, the retina can be divided into two main layers: the differentiated cell layer (DCL), consisting of newborn RGCs, amacrine cells, and horizontal cells, and the neuroblastic layer $(\mathrm{NbL})$ comprised of mainly retinal progenitor cell bodies with cones occupying the future photoreceptor layer along the apical surface (outlined in Fig. $1 B^{\prime}$ ). Other newborn neurons, including RGCs, begin to differentiate at the apical surface of the retina and migrate through the NbL to the DCL. First, we analyzed microglia density in the two major layers of the retina at e12.5 $(n=4)$, e14.5 $(n=4)$, and e16.5 $(n=6)$. Two-way ANOVA found a significant difference across ages $\left[F_{(2,22)}=33.12, p<0.0001\right]$ and retinal layers $\left[F_{(2,22)}=122.3, p<0.0001\right]$. At every time point assessed, microglial density was highest in the DCL by Sidak's multiplecomparisons test (Fig. $1 E$; e12.5, $p<0.0001$; e14.5, $p=0.0122$; e16.5, $p<0.0001$ ). We observed the majority of microglia in the DCL directly contacting Brn $3^{+}$RGCs. But due to the high density of RGCs, it was unclear whether this microglia-RGC contact was simply due to chance. Therefore, we analyzed the percentage of NbL microglia contacting migrating RGCs, where it was easier to determine meaningful interactions (Fig. $1 F, G ; n=4$, 4, and 6 animals at e12.5, e14.5, and e16.5). Even though retinal progenitors vastly outnumber migrating RGCs in the NbL, almost 50\% of microglia in the $\mathrm{NbL}$ contacted migrating Brn3 ${ }^{+}$RGCs at e14.5, which persisted at e16.5 (Fig. 1G).

Microglia are important for the elimination of apoptotic cells during development, and apoptosis facilitates microglia entry and positioning in the zebrafish CNS (Casano et al., 2016; Xu et al., 2016). Therefore, we also assessed the distribution and contact of microglia to cleaved caspase-3-positive $\left(\mathrm{CC}^{+}\right)$cells. Consistent with previous reports, overall apoptosis levels were fairly low at the time points assessed. Of total microglia present in the retina, only $\sim 15 \%$ contacted $\mathrm{CC}^{+}{ }^{+}$cells at e12.5 and $7 \%$ at e16.5 (Fig. $1 H ; n=4$ e12.5; $n=7$ e16.5). Therefore, microglia mainly reside in the DCL and primarily associate with neurons during embryonic retinal neurogenesis.

\section{Loss of colony stimulating factor 1 signaling conditionally and selectively depletes retinal microglia}

To determine their impact on neurogenesis, we designed a genetic strategy to eliminate microglia. Colony stimulating factor 1 receptor $(C s f 1 r)$ is essential for microglia survival in the brain (Erblich et al., 2011; Nandi et al., 2012) as well as the retina (Wang et al., 2016), and pharmacological inhibition of CSF1R signaling results in microglial death (Elmore et al., 2014). Because CSF1R is also expressed in neural progenitors (Nandi et al., 2012; Chitu et al., 2016), 


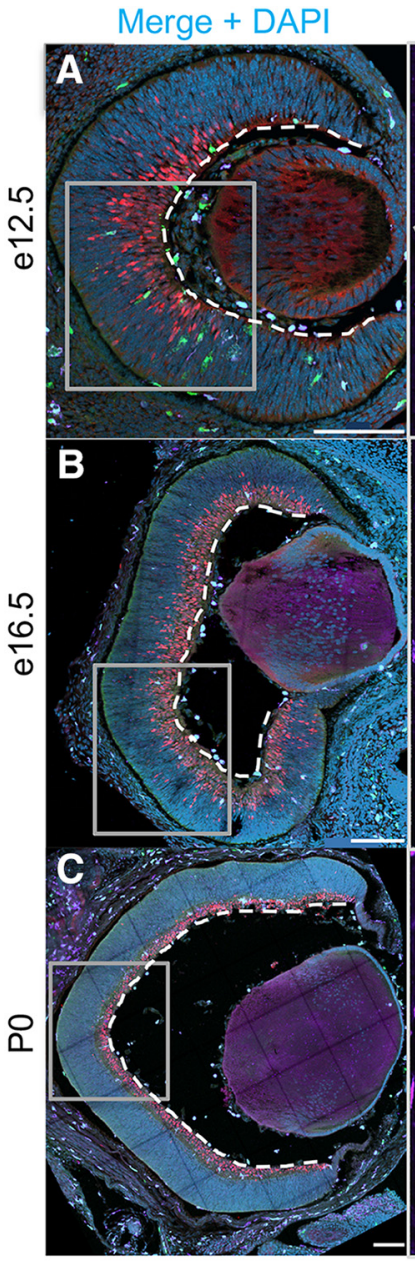

D
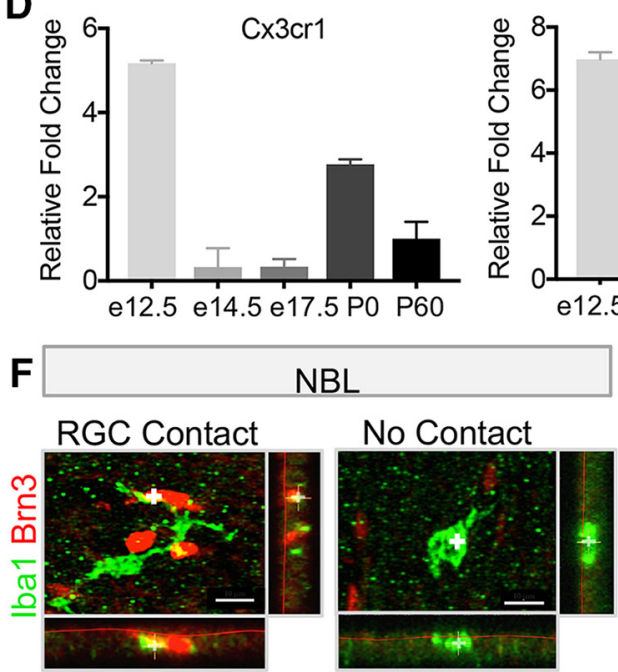

Iba1
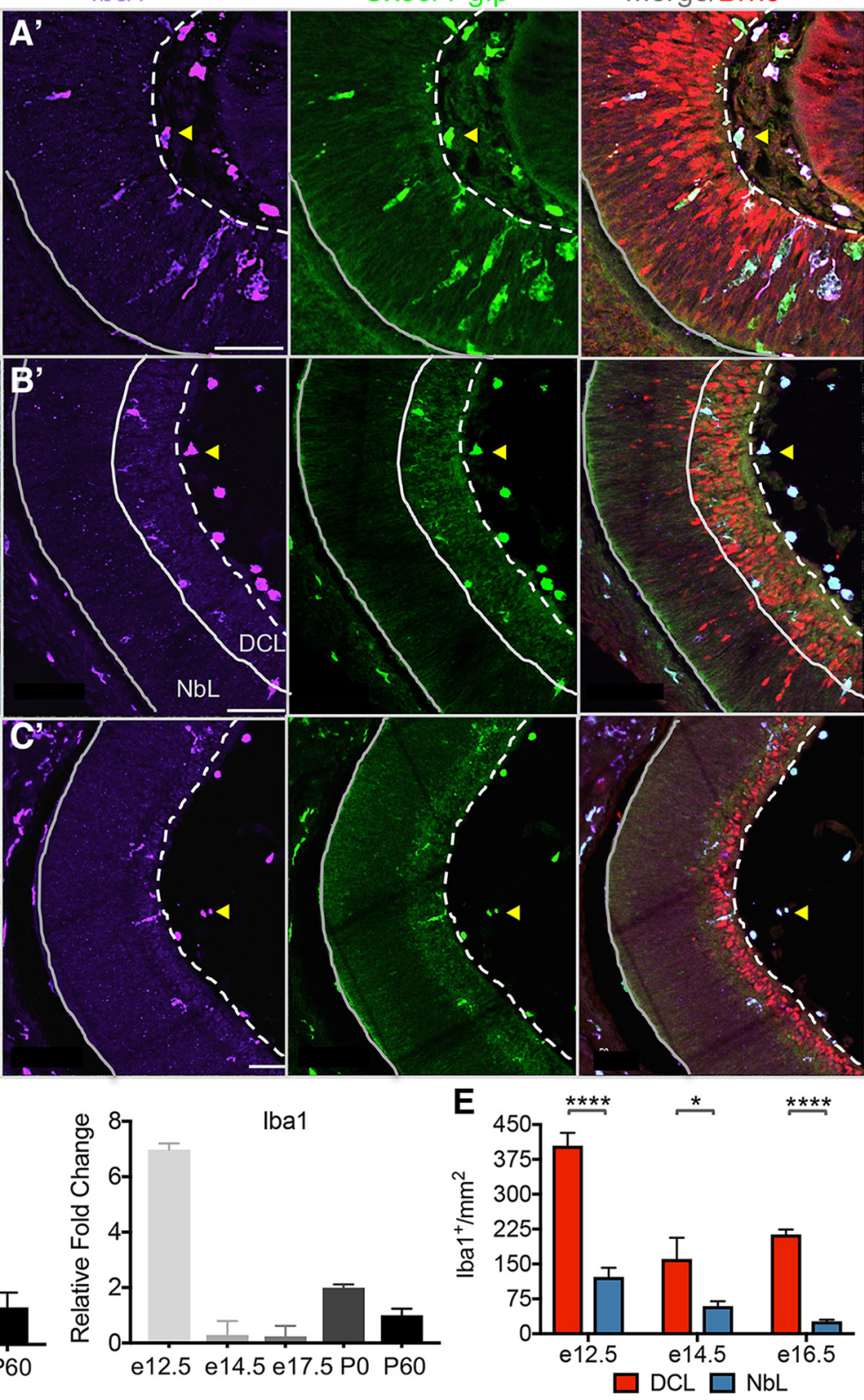

G

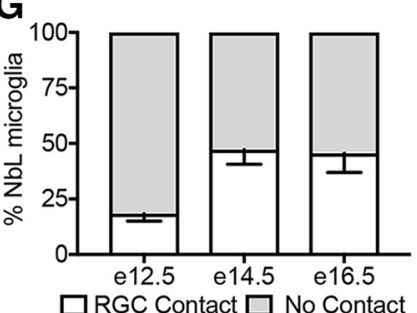

Merge/Brn3

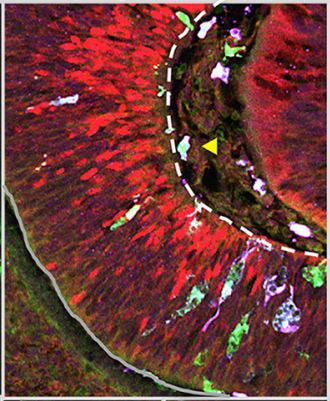

$\mathbf{H}$

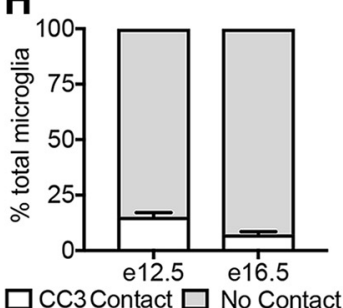

Figure 1. Microglial density is dynamic in the developing retina, and microglia primarily associate with newborn neurons. $A-C$, Representative confocal images of retinal cross sections and central regions $\left(\boldsymbol{A}^{\prime}-\boldsymbol{C}^{\prime}\right)$ at e12.5, e16.5, and P0: DAPI (blue), Iba1 (purple), Cx3cr1-gfp (green), and Brn3 (red). Dashed line indicates the boundary between the retina and vitreous where $\mathrm{Iba}^{+}{ }^{+} \mathrm{GFP}{ }^{+}$vitreal macrophages reside (yellow arrowheads). NbL and DCL outlined in $\boldsymbol{B}^{\prime}$. D, qRT-PCR of whole-retina samples over embryonic development. Levels of $\mathrm{Cx} 3 \mathrm{cr} 1$ and $\mathrm{Iba} 1$ expression at various ages relative to $\mathrm{P} 60$ and normalized to $\beta$ actin ( $n \geq 3$ each). $\mathrm{PPCR}$ graph represents fold change relative to P60. Error bar indicates the SEM of $\delta C_{\mathrm{t}}$ values. $E$, Microglial density in DCL and $\mathrm{NbL}$ at e12.5, e14.5, and e16.5. [ $n=4,4$, and 6 animals, respectively; two-way ANOVA: interaction, $F_{(2,22)}=9.265, p=0.0012 ;$ age, $F_{(2,22)}=33.12, p<0.0001$; retinal layer, $F_{(2,22)}=33.12, p<$ 0.0001; Sidak's multiple-comparisons: DCL vs NbL at e12.5, $t_{(22)}=8.942, p<0.0001 ; \mathrm{e} 14.5, t_{(22)}=3.206, p=0.0122 ; \mathrm{e} 16.5, t_{(22)}=7.24, p<0.0001$; Sidak's multiple-comparisons comparing

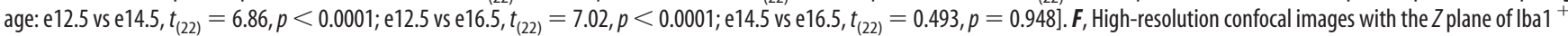
microglia in the $\mathrm{NbL}$ in contact with a migrating Brn3 ${ }^{+} \mathrm{RGC}$ (left) or not in contact (right). Iba ${ }^{+}$microglia (green) and Brn3 ${ }^{+} \mathrm{RGCs}$ (red). Z plane shown to the right and bottom of images. White cross represents point of interest. $\mathbf{G}$, Percentage of $\mathrm{Iba} 1^{+}$microglia in the NbL-contacting Brn3 ${ }^{+} \mathrm{RGCS}$ at e12.5, e14.5, and e16.5 $(n=4,4$, and 6 animals, respectively). $\boldsymbol{H}$, Percentage total $\mathrm{Iba} 1^{+}$microglia contacting $\mathrm{CC} 3^{+}$cells at e12.5 and e $16.5(n=4$ retinas, e12.5; $n=7$ retinas, e16.5). Scale bars: $100 \mu \mathrm{m}$ for whole-retina cross sections, $50 \mu \mathrm{m}$ for high-magnification central region, and $10 \mu \mathrm{m}$ for microglia contact in NbL. Graphs represent the mean; error bars indicate SEM. Four or five sections per retina were analyzed. ${ }^{* * * *} p<0.0001$. ${ }^{*} p<0.05$. 
A

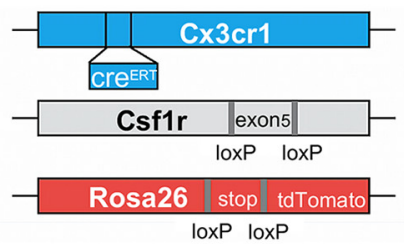

B

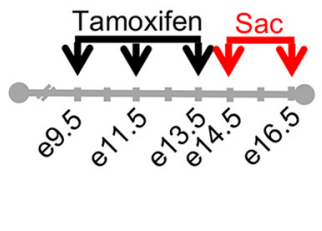

C

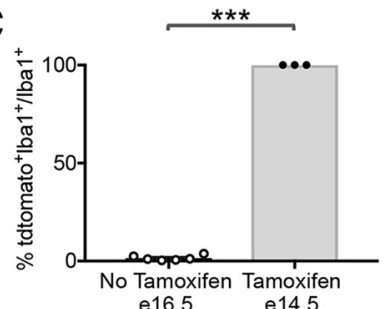

16.5

e14.5

D

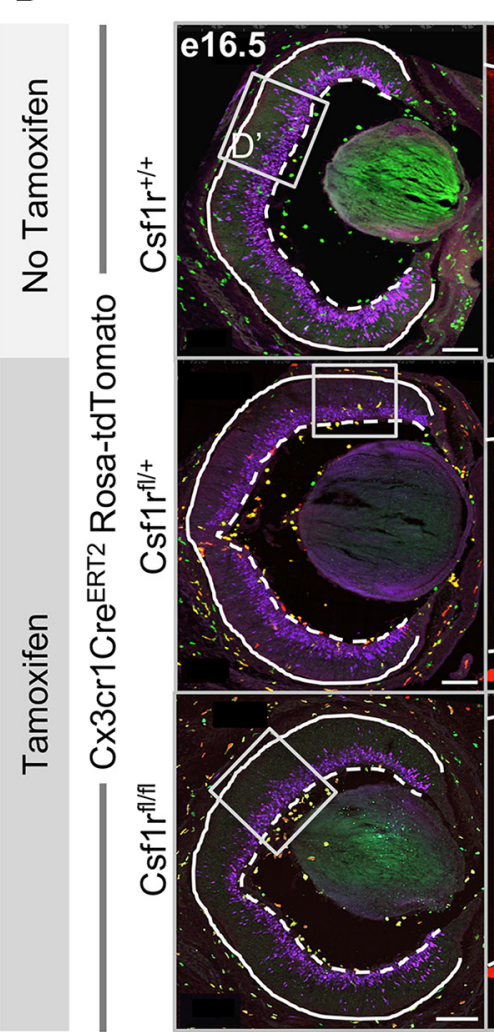

tdTomato

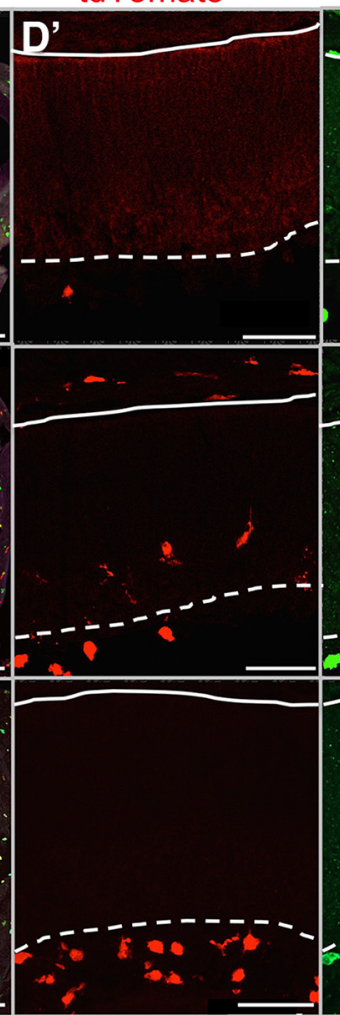

Iba1
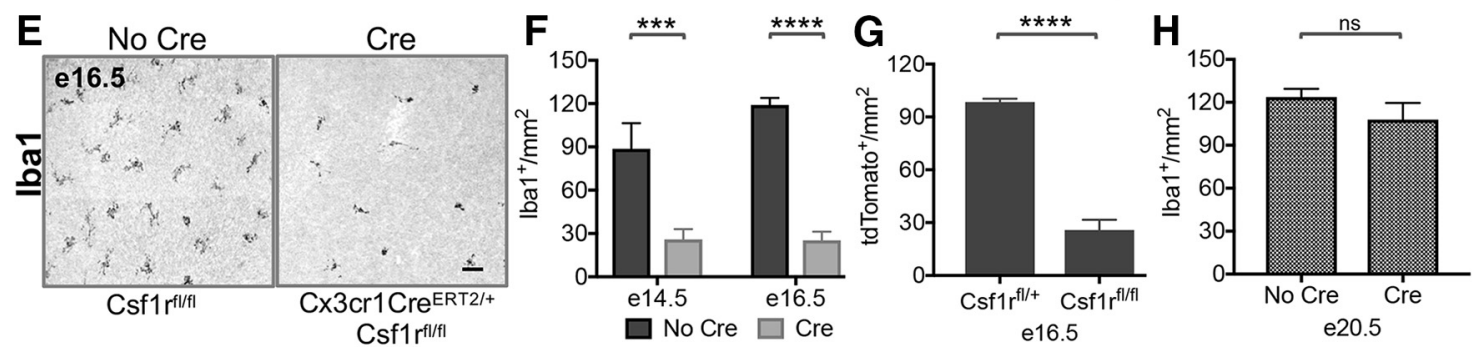

Figure 2. Conditional loss of colony stimulating factor 1 receptor depletes embryonic retinal microglia. $\boldsymbol{A}$, Genetic strategy for conditionally ablating microglia. $\boldsymbol{B}$, Tamoxifen dosing regimen to target embryonic retinal neurogenesis. Three doses of tamoxifen were administered by oral gavage to pregnant females every other day starting at e9.5 $(2,2$, and $3 \mathrm{mg}$ of $10 \mathrm{mg} / \mathrm{ml}$ tamoxifen in corn oil). C, Quantification of tdTomato ${ }^{+} \mathrm{Iba} 1^{+} / \mathrm{lba} 1^{+}$cells in whole-retina cross sections of $\mathrm{Cx} 3 \mathrm{cr} 1 \mathrm{cre}{ }^{\mathrm{ERT} 2 /+}{ }^{\text {Rosa }}{ }^{\text {tdtomato/+ }} \mathrm{Csf1r}^{+/+}$or fl/fl at e16.5 without tamoxifen and $\mathrm{Cx} 3 \mathrm{cr} 1 \mathrm{cre}{ }^{\mathrm{ERT} 2 /+}$ Rosa ${ }^{\text {tdtomato/+ }}$ at e14.5 with tamoxifen (e16.5, $\left.n=6 ; \mathrm{e} 14.5, n=3 ; t_{(7)} 125.1, p<0.0001\right)$. Individual dots represent means for each retina. $\boldsymbol{D}$, Retinal cross sections of e16.5 $\mathrm{Cx3}$ cr1cre ${ }^{\mathrm{ERT} 2 /+}$

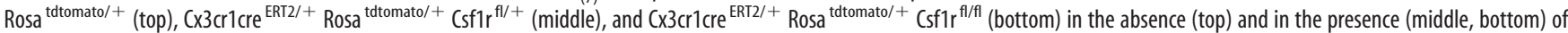

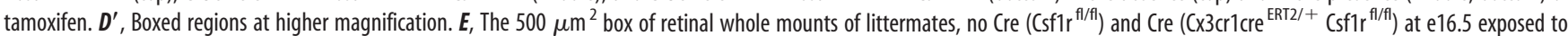
tamoxifen: Iba $1{ }^{+}$microglia (black). $\boldsymbol{F}$, Quantification of Iba ${ }^{+}$density at e14.5 and e16.5 in Cre retinas and no Cre littermate controls (e14.5 no Cre $n=5$, Cre $n=8$; e16.5 no Cre $n=6$, Cre $n=$ 6; two-way ANOVA: interaction, $F_{(1,21)}=2.821, p=0.1078$; Cre expression, $F_{(1,21)}=71.32, p<0.0001$; age $F_{(1,21)}=2.565, p=0.1242$; Sidak's multiple-comparisons test, e14.5 $t_{(21)}=4.814$,

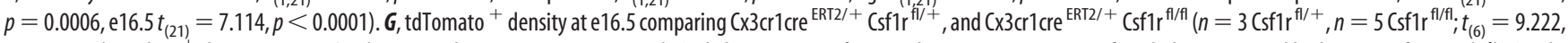
$p<0.0001) . \boldsymbol{H}$, Iba ${ }^{+}$density at e20.5/P0 $\left(n=3\right.$ each; $\left.t_{(4)}=1.21, p=0.293\right)$. Scale bars: $100 \mu \mathrm{m}$ for retinal cross sections, $50 \mu \mathrm{m}$ for whole mounts and higher magnification $\left(\mathbf{C}^{\prime}\right)$. Graphs represent mean with SEM. Four or five retinal sections per retina were analyzed. ${ }^{* * *} p<0.0001 .{ }^{* * *} p<0.001$.

we developed a targeted strategy crossing mice expressing a floxed Csf1r allele (Li et al., 2006) to the inducible Cx3cr1cre ${ }^{\text {ERT2 }}$ mouse line (Yona et al., 2013) to conditionally disrupt the Csflr gene in the myeloid lineage (Fig. 2A). Tamoxifen was administered to pregnant dams at e9.5, e11.5, and e13.5 by oral gavage
(Fig. 2B). To first test the specificity and efficiency of the system, we used a Rosa-tdTomato reporter line to examine Cre activity both in the absence of tamoxifen and following our three-dose regimen ( $\mathrm{Cx} 3 \mathrm{cr}_{1 \mathrm{cre}}{ }^{\mathrm{ERT} 2} \mathrm{Rosa}^{\text {tdTomato }}$ ) (Fig. $\left.2 C, D\right)$. In the absence of tamoxifen, very few Iba1 ${ }^{+}$cells $(1.58 \pm 0.54 \%)$ showed 
A
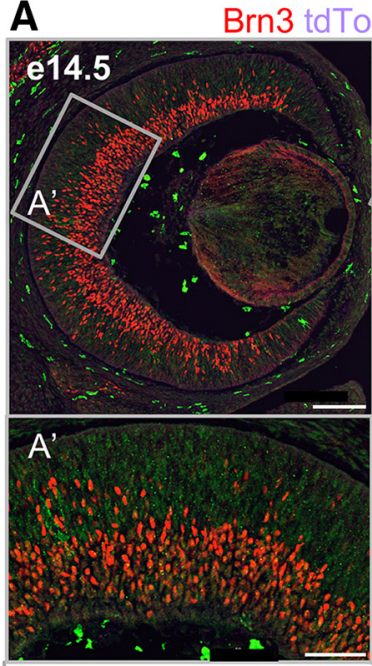

Control
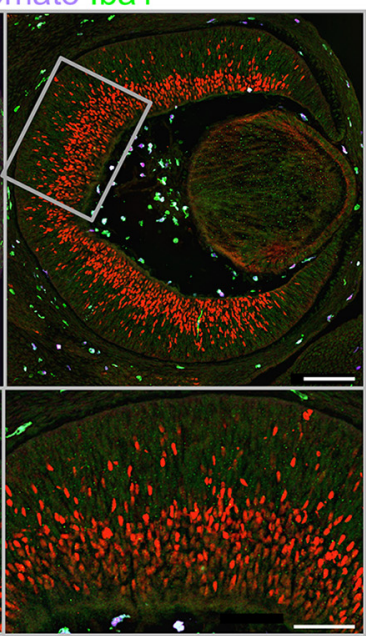

C

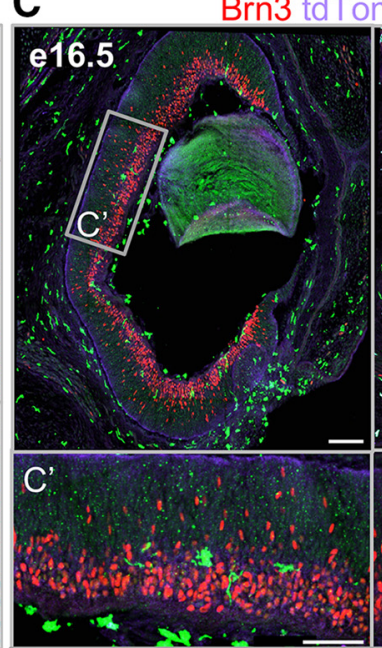

Control
Brn3 tdTomato lba1

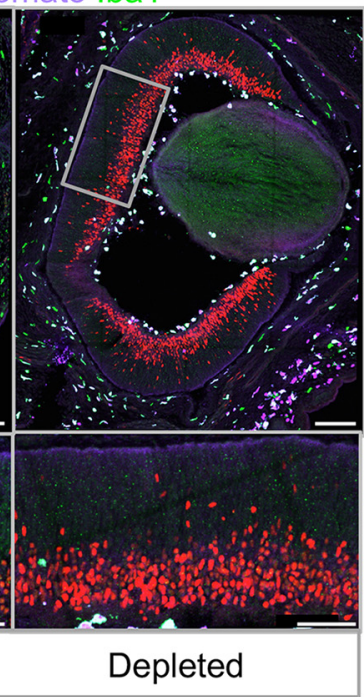

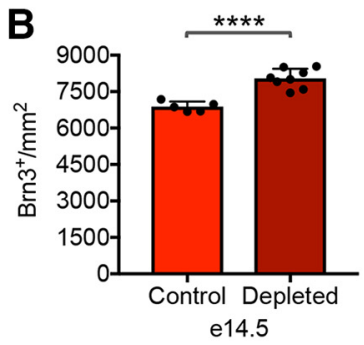

Depleted

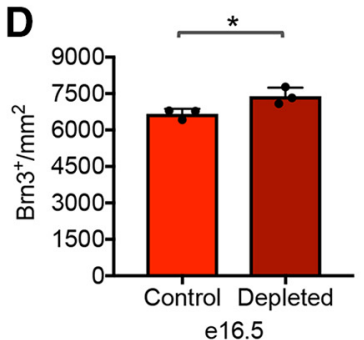

Figure 3. Loss of microglia increases RGC density. $\boldsymbol{A}$, Representative whole-retina cross sections of e14.5 control and depleted retinas illustrating area of analysis $\left(\boldsymbol{A}^{\prime}\right)$ : Brn $3^{+}$RGCs (red), Iba ${ }^{+}$ microglia (green), and tdTomato ${ }^{+}$(purple). $\boldsymbol{B}$, Quantification of dorsal central Brn3 ${ }^{+}$RGC density in controls and depleted at e14.5 ( $n=5$ control, $n=8$ depleted; $\left.t_{(11)}=6.025, p<0.0001\right)$. C, Representative whole-retina cross sections and dorsal central regions $\left(\boldsymbol{C}^{\prime}\right)$ of e16.5 control and depleted retinas: Brn3 ${ }^{+} \mathrm{RGCS}$ (red), Iba1 ${ }^{+}$microglia (green), and tdTomato ${ }^{+}$(purple). $\boldsymbol{D}$, Quantification of dorsal central Brn3 ${ }^{+}$RGC density in control and depleted retinas at e 16.5 ( $n=3$ each; $\left.t_{(4)}=3.074, p=0.0372\right)$. Scale bars: $100 \mu \mathrm{m}$ for whole retinas $(\boldsymbol{A}, \boldsymbol{C})$ and $50 \mu \mathrm{m}$ for higher magnification $\left(\boldsymbol{A}^{\prime}, \boldsymbol{C}^{\prime}\right)$. Graphs represent mean with SEM. Individual dots represent means for each retina. ${ }^{* * *} p<0.0001 .{ }^{*} p<0.05$.

Cre activity by tdTomato expression at e16.5, suggesting negligible background activity (Fig. $2 C, D$, top; $n=6$ ). In contrast, at e14.5, immediately following three doses of tamoxifen, $100 \%$ of ${\text { Iba }{ }^{+} \text {cells were tdTomato }}^{+}$(Fig. $2 C ; n=3 ; p<0.0001$ ), confirming the efficacy of $\mathrm{Cx} 3 \mathrm{cr} 1 \mathrm{cre}^{\mathrm{ERT} 2}$ in retinal microglia.

Following tamoxifen administration to pregnant dams (Fig. $2 B$ ), retinas from Cx3cr1cre ${ }^{\text {ERT2 }}$; Csf1r ${ }^{\text {fl/fl }}$ (Cre) e16.5 embryos displayed a substantial reduction in the number of $\mathrm{Ibal}^{+}$cells compared with littermate controls exposed to tamoxifen and homozygous for the floxed allele but lacking Cre expression (no Cre;Csf1r $\mathrm{r}^{\mathrm{fl} / \mathrm{fl}}$ ) (Fig. 2D-F). Embryos heterozygous for the floxed Csf1r allele ( $\mathrm{Cx} 3 \mathrm{cr}_{1} \mathrm{cre}^{\mathrm{ERT} 2}$; $\mathrm{Csf1} \mathrm{r}^{\mathrm{fl} /+}$ ) had a slight reduction in microglial density and therefore were not used as controls (Fig. $2 \mathrm{D}$, middle). In $\mathrm{Cx} 3 \mathrm{cr} 1 \mathrm{cre}^{\mathrm{ERT} 2} ; \mathrm{Csf1} \mathrm{r}^{\mathrm{fl} / \mathrm{fl}}$ retinas, we found a $70 \%$ reduction in microglial density at e14.5 compared with no Cre; Csfl $\mathrm{r}^{\mathrm{fl} / \mathrm{fl}}$ retinas $(n=5$, no Cre; $n=8$, Cre; Sidak's multiplecomparisons, $p=0.0006$; Cre, $25.98 \pm 7.06 \mathrm{Iba} 1 / \mathrm{mm}^{2}$; no Cre, $88.63 \pm 17.78 \mathrm{Iba} 1 / \mathrm{mm}^{2}$ ). At e16.5, microglial density was similarly reduced in $\mathrm{Cx} 3 \mathrm{cr} \mathrm{cre}^{\mathrm{ERT} 2} ; \mathrm{Csf1r}{ }^{\mathrm{fl} / \mathrm{fl}}$ retinas $(25.25 \pm 6.10$ $\left.\mathrm{Iba} 1 / \mathrm{mm}^{2}\right)$, despite the general increase in microglial density in the control, no Cre; Csfl $\mathrm{r}^{\mathrm{fl} / \mathrm{fl}}\left(119.01 \pm 4.88 \mathrm{Ibal} / \mathrm{mm}^{2}\right)$ (Fig. $2 F$; $n=6$, no Cre; $n=6$, Cre; Sidak's multiple-comparisons, $p<$ 0.0001). Surviving microglia from $\mathrm{Cx} 3 \mathrm{cr} 1 \mathrm{cre}^{\mathrm{ERT} 2}$; $\mathrm{Csf1r} \mathrm{r}^{\mathrm{fl} / \mathrm{fl}}$ retinas, in general, had increased soma size and reduced branching (Fig. 2E). To confirm that microglia were absent and not simply downregulating Iba1, we assessed the number of tdTomato ${ }^{+}$ cells in $\mathrm{Cx} 3 \mathrm{cr} 1 \mathrm{cre}^{\mathrm{ERT} 2}$; Rosa-tdTomato; Csflr $\mathrm{r}^{\mathrm{fl} / \mathrm{fl}}$ retinas and found a similar reduction in density, to $25.83 \pm 5.81 \mathrm{tdTomato} /$ $\mathrm{mm}^{2}$ [Figure $2 G ; n=3$ controls ( $\mathrm{Cx} 3 \mathrm{cr} 1 \mathrm{cre}{ }^{\mathrm{ERT} 2}$; RosatdTomato; Csf1r $\left.{ }^{\mathrm{fl} /+}\right) ; n=5 \mathrm{Cx} 3 \mathrm{crlcre}^{\mathrm{ERT} 2}$; Rosa-tdTomato; Csf1 $\left.\mathrm{r}^{\mathrm{fl} / \mathrm{fl}} ; p<0.0001\right]$. Microglial density returned to WT levels $\sim$ e20.5/P0 (Fig. $2 H ; n=3$ each; $p=0.293$ ), consistent with reports of microglia repopulation after depletion in the adult CNS (Elmore et al., 2014; Huang et al., 2018a,b).

There was significant tdTomato ${ }^{+}$expression outside of the retina as CX3CR1 is expressed in other myeloid cells in the eye, including in vitreal macrophages. However, $\mathrm{Cx} 3 \mathrm{cr} 1^{+}$microglia within the retina were selectively vulnerable to Csf1r loss, congruous with published work (Elmore et al., 2014, 2015; Hilla et al., 2017). Vitreal macrophages were indeed increased in $\mathrm{CX} 3 \mathrm{cr} 1 \mathrm{cre}{ }^{\mathrm{ERT} 2} ; \mathrm{Csf1r}{ }^{\mathrm{fl} / \mathrm{fl}}$ retinas compared with littermate controls (data not shown; $n=3$ each; two-tailed Student's $t$ test, $p=0.0006)$. Therefore, retinas from Cx3cr1cre ${ }^{\text {ERT2 }}$; Csf1 $\mathrm{r}^{\mathrm{fl} / \mathrm{fl}}$ animals (referred to as "depleted" hereafter) show a significant and profound loss of microglia following tamoxifen exposure, without depletion of surrounding macrophage populations during a specific time window and without disrupting Csf1r signaling in progenitors. This genetic strategy allows targeted assessment of microglia function during embryonic retinal neurogenesis. 
A
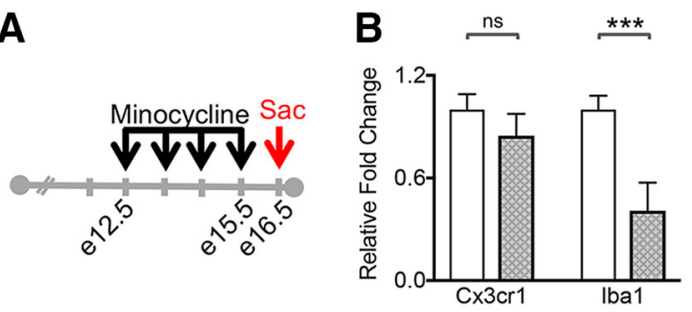

$\square$ Control Minocycline
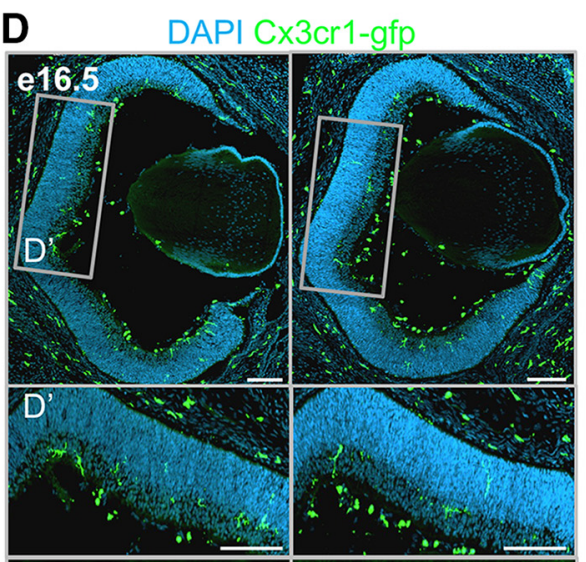

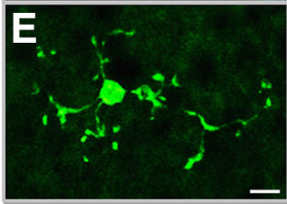

Control
$\mathbf{F}$

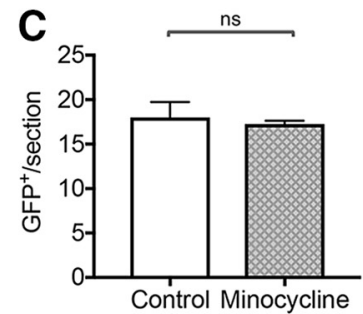

Brn3 Cx3cr1-gfp
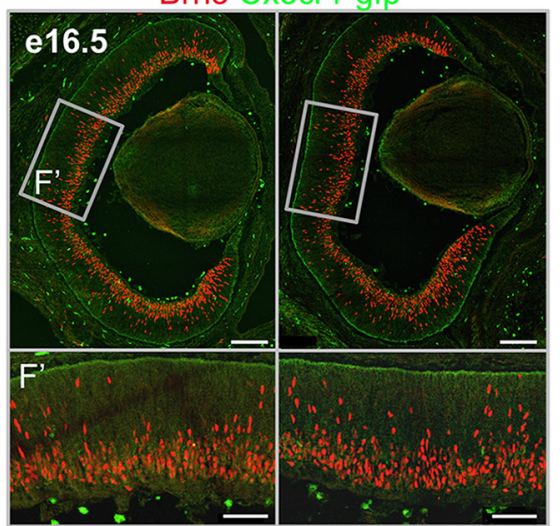

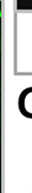 \\ G}

Control

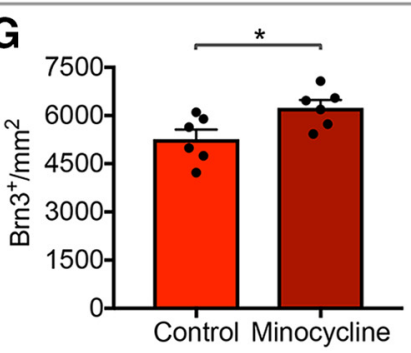

$\mathrm{H}$

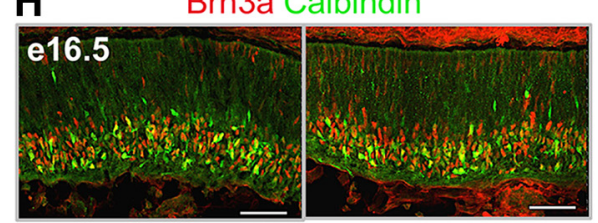

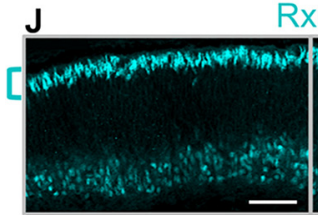

Control

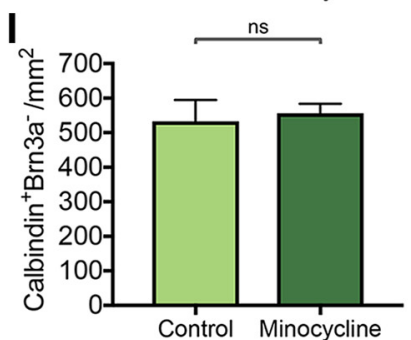

K

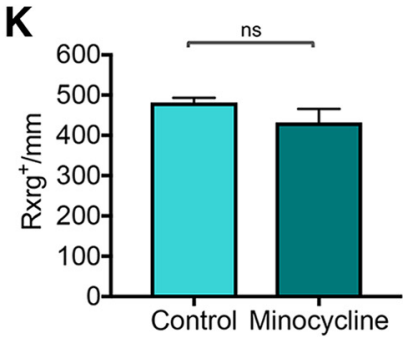

Figure 4. Pharmacological inhibition of microglia increases RGC density with no change in other early born cell types. $A$, Minocycline dosing regimen targeting embryonic retinal neurogenesis. The $120 \mathrm{mg} / \mathrm{kg}$ of minocycline or vehicle alone was given by oral gavage once daily for $4 \mathrm{~d}$ beginning at e12.5. $\boldsymbol{B}$, Whole-retina qRT-PCR at e16.5 analyzing microglia transcripts $\mathrm{C} 3 \mathrm{cr} 1$ and Iba1 $\left(n=3\right.$ control, $n=10$ minocycline-treated; $C \times 3$ cr1 $t_{(11)}=0.9771, p=0.350 ;$ Iba1 $\left.t_{(11)}=4.127, p=0.0017\right)$, normalized to $\beta$ actin and fold change relative to vehicle only controls. qPCR graph represents fold change. Error bars indicate the SEM of $\delta C_{t}$ values. C, Quantification of GFP ${ }^{+}$cells in control and minocycline-treated retinal cross sections ( $n=9$ animals each; $t_{(16)}=$ $0.4183 p=0.681$ with Welch's correction). $\boldsymbol{D}$, Representative retinal cross sections at e16.5 of control and minocycline-treated retinas: DAPI (blue) and CX3cr1-gfp (green). $\boldsymbol{C}^{\prime}$, Higher-magnification images of dorsal central region. $\boldsymbol{E}$, High-magnification view of individual $\mathrm{GFP}^{+}$microglia from retinal whole mounts. $\boldsymbol{F}$, Representative retinal cross sections of control and minocyclinetreated animals at e16.5 with higher-magnification analyzed dorsal central region of RGCS. Higher-magnification view below $\left(\boldsymbol{F}^{\prime}\right)$ : $\mathrm{Brn}^{+} \mathrm{RGCS}(\mathrm{red})$ and $\mathrm{GFP}^{+}$microglia (green). G, Quantification of dorsal central Brn3 ${ }^{+} \mathrm{RGC}$ density in control and
Microglia regulate RGC density in the embryonic retina

Because microglia closely associate with newborn neurons, we asked whether microglia influence their numbers. We initially focused on RGCs because they are the first-born and most abundant neuron of the retina at early embryonic stages. Mouse RGC genesis initiates at e10.5 and concludes around birth, with peak production at $\sim$ e13.5-e14.5 (Sidman, 1961; Young, 1984). We performed immunostaining for Brn3 on cryosections of depleted and control embryos at e14.5 and e16.5 and analyzed the density of $\mathrm{Brn} 3^{+}$ RGCs in a fixed area of the retina, the dorsal central region. Compared with littermate controls, depleted retinas had increased RGC density during peak RGC generation at e14.5 (control, $6880 \pm$ 94.03; depleted, $8045 \pm 139.4 \mathrm{Brn} 3^{+} /$ $\mathrm{mm}^{2}$ ) (Fig. $3 A, B ; n=5$ control; $n=8$ depleted; $p=8.6 \mathrm{E}-05$ ) as well as $48 \mathrm{~h}$ later, at e16.5 (control, $6666 \pm 120.5$; depleted, $7393 \pm 203.6 \mathrm{Brn}^{+} / \mathrm{mm}^{2}$ ) (Fig. $3 C, D$; $n=3$ each; $p=0.037)$. Therefore, these data suggest that microglia normally restrict RGC number during embryonic retinal development.

To confirm our findings that microglia were regulating RGC density, we used pharmacological inhibition of microglia to selectively perturb microglial function. Minocycline, a tetracycline derivative, is commonly used to suppress microglial activity during development (Schafer et al., 2012; Cunningham et al., 2013; Kobayashi et al., 2013; Ueno et al., 2013; ShigemotoMogami et al., 2014). Minocycline or vehicle alone was administered once a day to pregnant dams from e12.5 to e15.5 by oral gavage (Fig. 4A). First, we confirmed microglial inhibition by whole-retina qRTPCR. C $x 3 \mathrm{cr} 1$, which is not altered with microglial activation, was not signifi-

\section{$\leftarrow$}

minocycline-treated retinas at e16.5 ( $n=6$ animals each; $t_{(10)}=2.53, p=0.0299$ ). Individual dots represent means for each retina. $\boldsymbol{H}$, Representative images of dorsal central region analyzing horizontal and amacrine cells: Brn3a ${ }^{+}$RGCs (red) and calbindin $^{+}$(green). I, Quantification of calbindin ${ }^{+}$ $\mathrm{Brn3a}{ }^{-}$cells at e16.5 of control and minocycline-treated retinas $\left(n=6\right.$ control, $n=5$ treated; $t_{(9)}=0.318, p=0.758$ ). $J$, Representative images of dorsal central region Rxr $\gamma^{+}$cells along the apical surface. Rxr $\gamma^{+}$(teal). $\boldsymbol{K}$, Quantification of Rxr $\gamma^{+} \mathrm{Brn}^{-}{ }^{-}$cell density along $300 \mu \mathrm{m}$ of the apical surface at e16.5 of control and minocycline-treated retinas ( $n=4$ control, $n=4$ treated; $t_{(6)}=1.394, p=0.213$ ). Scale bars: $100 \mu \mathrm{m}$ for whole-retina cross sections $(\boldsymbol{D}, \boldsymbol{F})$ and $50 \mu \mathrm{m}$ for higher-magnification central regions in $\left(\boldsymbol{D}^{\prime}, \boldsymbol{F}^{\prime}, \boldsymbol{H}, \boldsymbol{J}\right), 10 \mu \mathrm{m}$ for individual microglia $(\boldsymbol{E})$. Graphs represent mean \pm SEM. ${ }^{* * *} p<0.001 .{ }^{*} p<0.05$. 
A
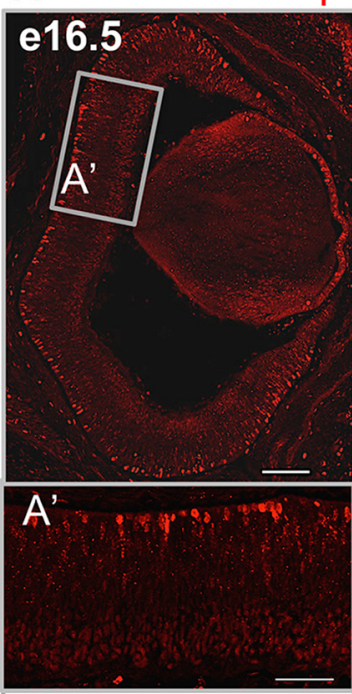

Control
$\mathrm{pH} 3$
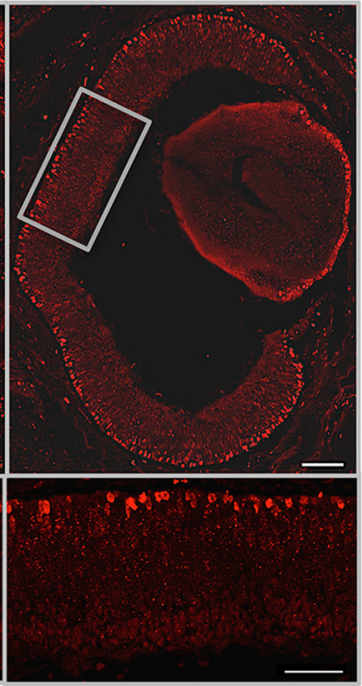

Minocycline
B

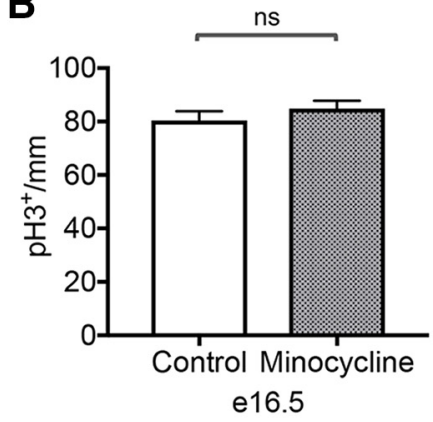

C

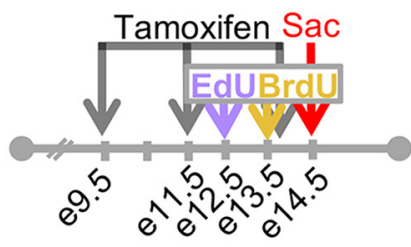

D
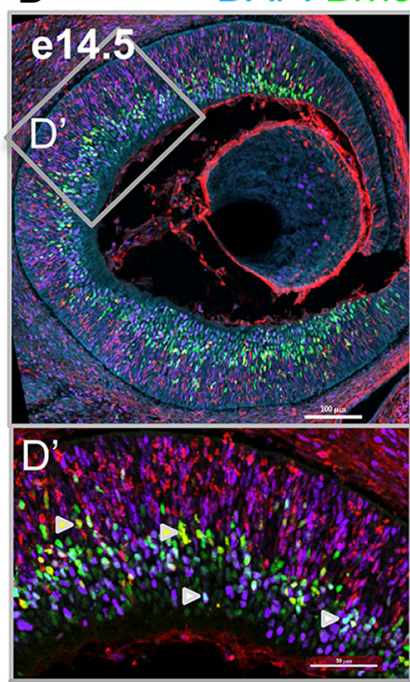

Control
BrdU EdU
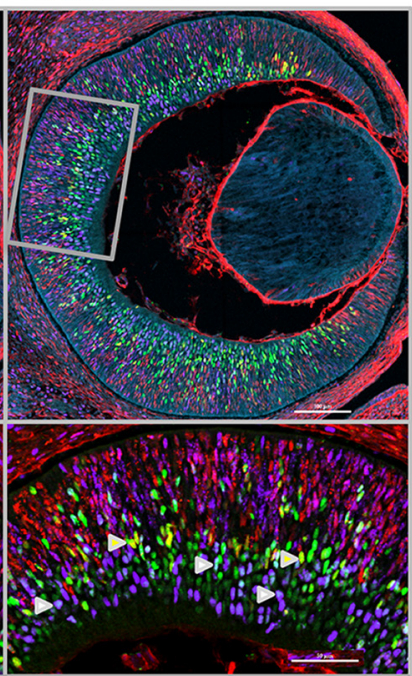

Depleted

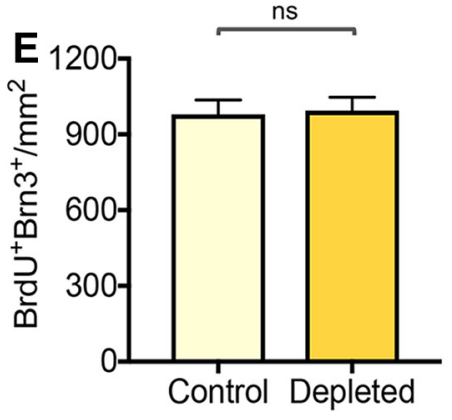

$\mathbf{F}$

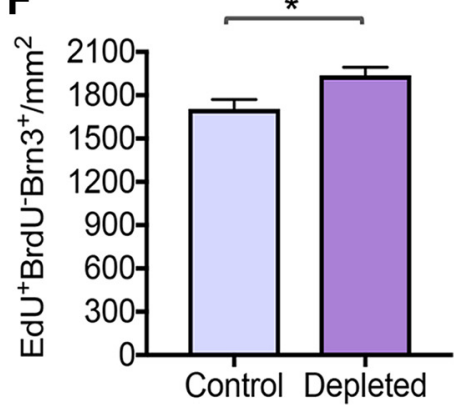

Figure 5. Perturbation of microglia does not change retinal progenitor proliferation or RGC genesis. $\boldsymbol{A}$, Retinal cross sections of control and minocycline-treated retinas at e16.5 with higher magnified analyzed dorsal central region $\left(\boldsymbol{A}^{\prime}\right)$ of pH3 (red). $\boldsymbol{B}$, Density of pH3 along $300 \mu \mathrm{m}$ length of apical surface of dorsal central region of control and minocycline retinas $(n=6$ animals each; $\left.t_{(10)}=0.978, p=0.351\right)$. C, Dosing regimen for tamoxifen (e9.5, e11.5, e13.5), EdU (e12.5), and BrdU (e13.5) injections. D, Representative retinal cross sections of control and microglia depleted animals at e14.5 injected with EdU at e12.5 and BrdU at e13.5, with higher magnified analyzed dorsal central region ( $\boldsymbol{D}^{\prime}$ ): DAPI (blue), Brn3 ${ }^{+}$RGCs (green), BrdU (red), and EdU (purple). Yellow arrowheads indicate RGCs born between e13.5 and e14.5 (BrdU ${ }^{+}$EdU $^{+/-}$Brn3 $^{+}$). White arrowheads indicate RGCs born between e12.5 and e13.5 (EdU ${ }^{+}$BrdU ${ }^{-}$Brn3 ${ }^{+}$). $\boldsymbol{E}_{,}$Quantification of $\mathrm{RGCs}$ born between e13.5 and e14.5 (BrdU $\left.{ }^{+} \mathrm{EdU}^{+/-} \mathrm{Brn}^{+}\right)$in control and depleted retinas $\left(n=8\right.$ animals $/ 13$ retinas controls, $n=7$ animals $/ 10$ retinas depleted; $\left.t_{(21)}=0.190, p=0.8511\right)$. $\boldsymbol{F}$, Quantification of RGCs born between e 12.5 and e 13.5 (EdU $\left.{ }^{+} \mathrm{BrdU}^{-} \mathrm{Brn}^{+}{ }^{+}\right)$in control and depleted retinas $\left(n=5\right.$ animals $/ 10$ retinas controls, $n=3$ animals $/ 6$ retinas depleted; $t_{(14)}=2.45$, $p=0.0279)$. Scale bars: $100 \mu \mathrm{m}$ for whole-retina cross sections $(\boldsymbol{A}, \boldsymbol{D})$ and $50 \mu \mathrm{m}$ central regions $\left(\boldsymbol{A}^{\prime}, \boldsymbol{D}^{\prime}\right)$. Graphs represent mean with SEM. ${ }^{*} p<0.05$.

cantly changed, whereas Ibal mRNA was reduced nearly $60 \%$ in minocycline-treated retinas compared with vehicle-only controls, suggesting efficient microglial inhibition (Bosco et al., 2008; Kobayashi et al., 2013) (Fig. $4 B ; n=3$ control; $n=10$ minocycline; Ibal $p=2.2 \mathrm{E}-05 ; \mathrm{Cx} 3 \mathrm{cr} 1 p=0.159)$. Overall, microglial density, distribution, and morphology were unaffected following minocycline treatment (Fig. $4 C-E ; n=9$ each; $p=0.686$ ).

Analogous to depletion experiments, we observed a significant increase in RGC density in minocycline-treated retinas com- pared with controls (Fig. $4 F, G ; n=6$ each; $p=0.0299$ ). To determine whether other early born cell types were affected, we

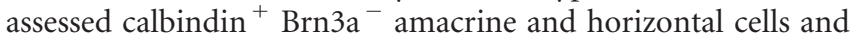
found no significant difference with treatment (Fig. $4 H, I ; n=6$ control; 5 minocycline; $p=0.758$ ). We also examined control and minocycline-treated retinas at P6 after amacrine cell genesis is complete and observed no consistent change in calbindin + amacrine cell density (data not shown). Similarly, cone $\left(\operatorname{Rxr} \gamma^{+} \mathrm{Brn}^{-}\right)$density was unchanged with minocycline treat- 
A

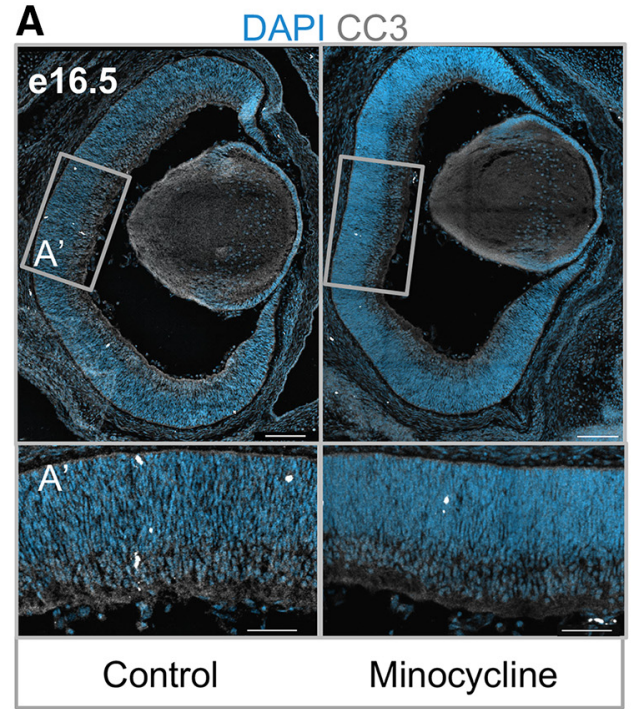

B

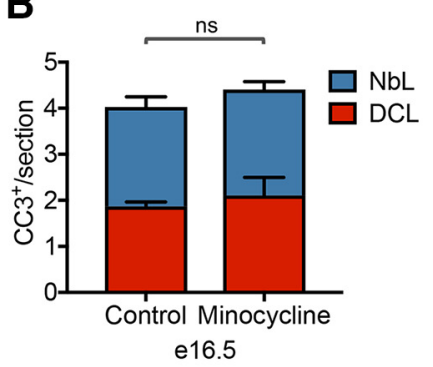

D

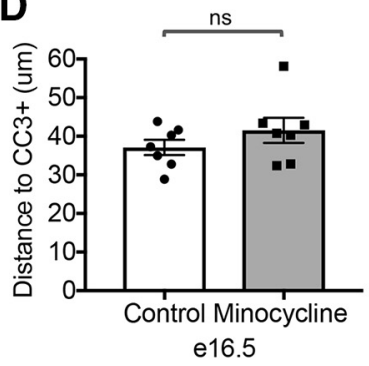

C

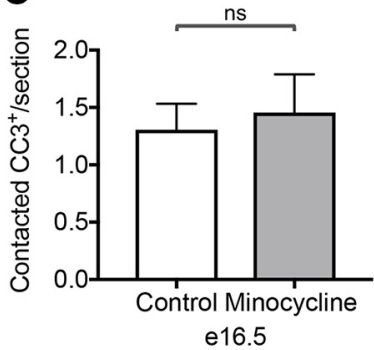

E

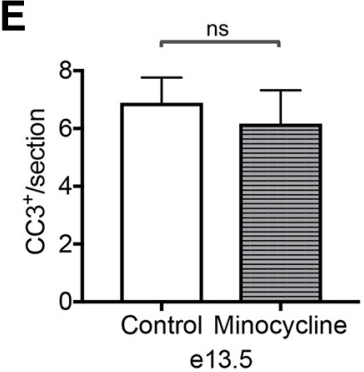

Figure 6. Inhibition of microglia does not change retinal cell apoptosis or alter microglial contact with apoptotic cells. $A$, Representative retinal cross sections of control and minocycline-treated animals at e16.5 with higher magnification $\left(\boldsymbol{C}^{\prime}\right)$ : DAPI (blue) and CC ${ }^{+}$apoptotic cells (white). $\boldsymbol{B}, C_{C} 3^{+}$cells at e16.5 of control and minocycline-treated retinas $[n=6$ animals each; two-way ANOVA: interaction, $F_{(1,20)}=0.039, p=0.846$; treatment, $F_{(1,20)}=0.597, p=0.449$; retinal layer, $F_{(1,20)}=0.9473, p=0.342 ;$ Sidak's multiple-comparisons: minocycline vs control $D C L, t_{(20)}=$ $\left.0.685, p=0.7511 ; \mathrm{NbL}, t_{(20)}=0.407, p=0.903\right]$. C, Number of CC3 ${ }^{+}$cells at e16.5 contacted by microglia $\left(n=7\right.$ each; $\left.t_{(12)}=0.3712, p=0.717\right)$. $D$, Average distance of microglia to a CC3 ${ }^{+}$ cell. Each dot represents the mean distance for a particular retina $\left(n=7\right.$ each; $\left.t_{(12)}=1.162, p=0.268\right) . E, C C 3^{+}$cells at e13.5 of control and minocycline-treated retinas ( $n=3$ animals each; $\left.t_{(4)}=0.498, p=0.645\right)$. Scale bars: $100 \mu \mathrm{m}$ for whole-retina cross sections $(\boldsymbol{A})$ and $50 \mu \mathrm{m}$ higher-magnification central regions $\left(\boldsymbol{A}^{\prime}\right)$. Graphs indicate mean with SEM. Individual dots represent individual retinas.

ment (Fig. 4J; $n=4$ each; $p=0.213$ ). Overall, these data confirm our results from depletion experiments and further suggest that microglial function, modulated by minocycline, is required to regulate $\mathrm{RGC}$ density.

Perturbation of microglia does not change retinal progenitor proliferation, RGC genesis, or RGC apoptosis

To determine whether more RGCs were produced, we first assessed progenitor proliferation in minocycline-treated and control retinas. We reasoned that, if microglial perturbation was increasing differentiation of RGCs, normally mitotic progenitors might exit the cell cycle and, consequently, be diminished in minocycline-treated retinas. However, we did not observe a change in actively cycling progenitors in the $\mathrm{G} 2$ to $\mathrm{M}$ transition $\left(\mathrm{pH}^{+}\right.$) following minocycline treatment at e16.5 (Fig. $5 \mathrm{~A}, \mathrm{~B}$; $n=6$ each; $p=0.351$ ).

To test whether there was an increase in RGC genesis following microglia perturbation, we labeled RGCs with BrdU during a specific time window in depleted and control retinas. BrdU was administered to pregnant females at e13.5 and euthanized $24 \mathrm{~h}$ later, when RGC density was already increased in depleted retinas (Fig. 5C). There was no significant difference in RGCs born within this $24 \mathrm{~h}$ time window $\left(\mathrm{BrdU}^{+} \mathrm{Brn}^{+}\right)$in depleted versus control animals (Fig. $5 D, E ; n=8$ animals/13 retinas controls; $n=7$ animals/10 retinas depleted; $p=0.851$ ), suggesting that microglia are not regulating RGC differentiation. We next performed a longer pulse to determine whether, instead, newly generated RGCs were persisting in depleted retinas relative to controls. EdU was administered at e12.5, BrdU at e13.5, and animals were euthanized at e14.5 (Fig. 5C). Thus, RGCs born between e12.5 and e13.5 were $\mathrm{EdU}^{+}$and $\mathrm{BrdU}^{-}$. Compared with littermate controls, RGCs born between e12.5 and e13.5 were significantly increased in depleted retinas at e14.5 (Fig. 5 D, F; $n=$ 5 animals/ 10 retinas controls; $n=3$ animals/ 6 retinas depleted; $p=0.0279)$. Therefore, these results suggest that microglia are not influencing RGC differentiation but instead regulating the survival of newborn RGCs $24-48 \mathrm{~h}$ after their birth.

To test whether microglia normally restrict RGC survival, we first analyzed apoptosis in minocycline-treated retinas and controls by CC3 immunostaining. If microglia were normally promoting apoptosis, we would expect to see a decrease in total number of $\mathrm{CC}^{+}$cells with microglial inhibition, or an increase in $\mathrm{CC}^{+}$cells if microglia were simply clearing dying RGCs. However, at e16.5, there was no significant change in the total number of $\mathrm{CC}^{+}$cells in minocycline-treated retinas compared with controls (Fig. $6 A, B ; n=6$ each; $p=0.731$ ) and no decrease specifically in the DCL (Fig. 6B). Further, we did not observe a change in the number of $\mathrm{CC}^{+}$contacted by microglia (Fig. $6 \mathrm{C}$; $n=7$ each; $p=0.717$ ) or a significant difference in the average distance of microglia to $\mathrm{CC}^{+}{ }^{+}$cells following treatment (Fig. $6 D$; $n=7$ each; $p=0.268$ ). Therefore, minocycline treatment does not change overall apoptosis levels or inhibit microglial migration or contact with $\mathrm{CC}^{+}$cells. To assess whether apoptosis could be altered during the time window in which we saw an increase in RGCs by birth-dating analysis (Fig. $5 D, F$ ), we gave animals a dose of minocycline at e12.5 and e13.5 and analyzed $2 \mathrm{~h}$ later. However, there was still no significant change in the number of apoptotic cells (Fig. $6 E ; n=3$ each; $p=0.645$ ). Together, our data suggest that microglia normally limit the number of RGCs, but not by inducing CC3-dependent apoptosis or by passive clearance of apoptotic RGCs.

\section{Microglia interact with non-CC3 ${ }^{+}$RGCs at embryonic stages}

Because there was no change in activated CC3 expression in minocycline-treated animals and no change in RGC genesis, we hypothesized that microglia might eliminate non-CC ${ }^{+}$RGCs. Consistent with this hypothesis, we observed many phagocytosis events at e12.5 and e13.5 in retinal whole mounts by confocal 

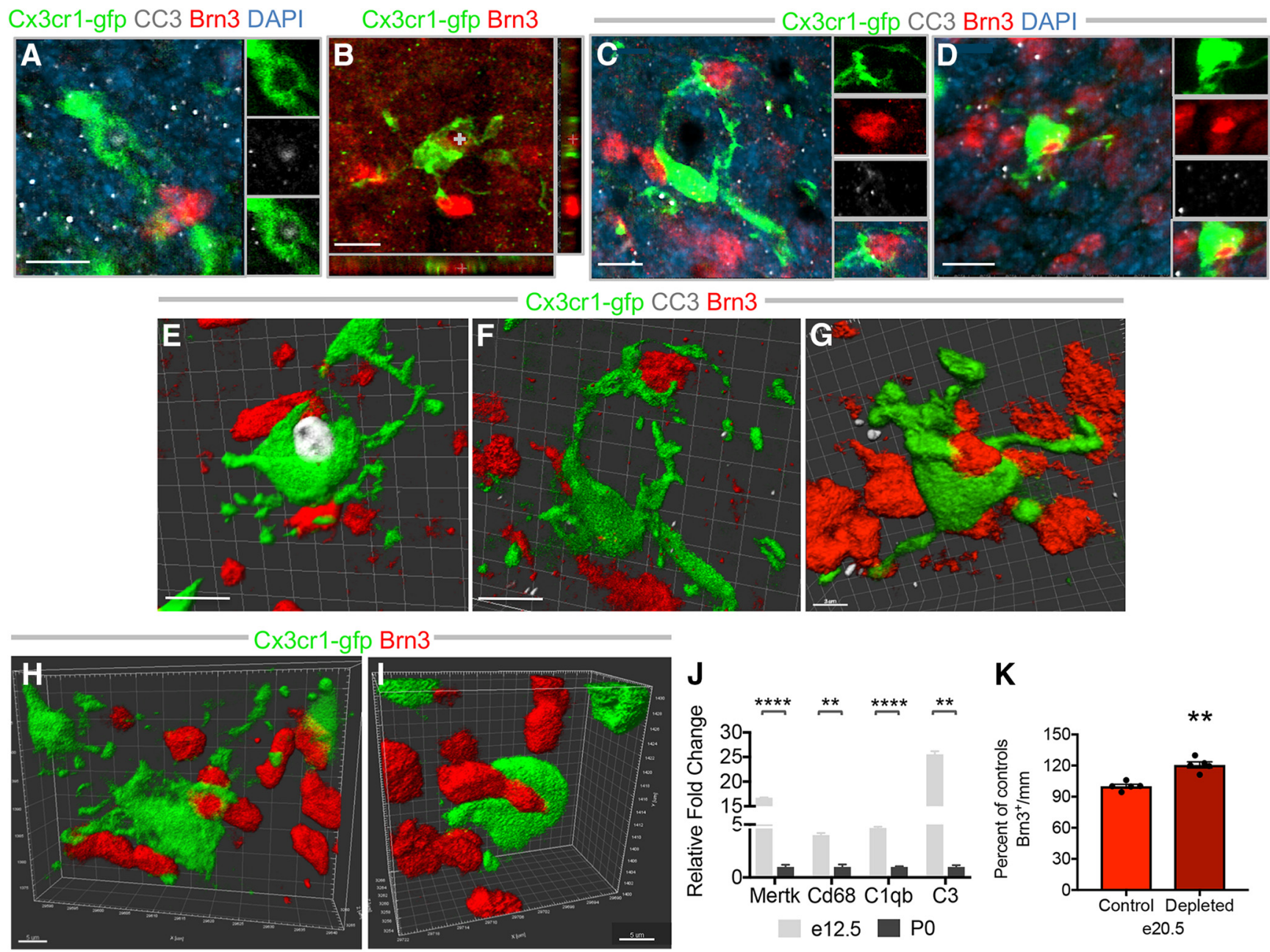

Figure 7. Microglia are phagocytic at embryonic stages and interact with RGCS. $A$, High-resolution confocal image of microglial engulfment of an apoptotic cell (CC $\left.3^{+}\right)$: DAPI (blue), Cx3cr1-gfp ${ }^{+}$microglia (green), Brn3 ${ }^{+}$RGCs (red), and CC3 ${ }^{+}$(white). B, Microglia engulfing Brn3 ${ }^{+}$RGC. Right, bottom, Z planes: Cx3cr1-gfp ${ }^{+}$microglia (green) and Brn3 ${ }^{+}$RGCs (red). C, D, Microglia interacting with non-CC3 ${ }^{+} \mathrm{RGCS}$ : DAPI (blue), $\mathrm{Cx} 3 \mathrm{Cr} 1$-gfp ${ }^{+}$microglia (green), Brn $3^{+} \mathrm{RGCS}$ (red), and CC ${ }^{+}$(white). E-I, IMARIS-based 3 D reconstruction of microglia interacting with RGCs: Cx3cr1-gfp ${ }^{+}$microglia (green), Brn3 ${ }^{+}$RGCs (red), and CC ${ }^{+}$(white). $\boldsymbol{F}$, Reconstruction of $\boldsymbol{C}$. $\boldsymbol{G}$, Reconstruction of $\boldsymbol{D} . \boldsymbol{J}$, Genes associated with phagocytosis assessed at e12.5 relative to P0 by whole-retina $q$ RT-PCR. Normalized to $\beta$ actin $\left(n=3\right.$ each; Mertk, $t_{(4)}=18.74, p<0.0001 ;\left(\mathrm{Cd} 68, t_{(4)}=6.71, p=0.0026 ; t_{(4)}=16.41 ;\left(1 \mathrm{qb}, p<0.0001 ;\left(3, t_{(4)}=7.33, p=0.0018\right)\right.\right.$. qPCR graph represents fold change. Error bar indicates the SEM of $\delta C_{\mathrm{t}}$ values. $\boldsymbol{K}$, Percentage of $\mathrm{Brn} 3^{+} \mathrm{RGC}$ density in depleted retinas normalized to littermate control retinas at e20.5/P0 ( $n=5$ retinas/3 animals each; one-sample $t$ test, $t_{(4)}=6.898, p=0.0023$ ). Scale bars: $\boldsymbol{E}, \boldsymbol{F}, 10 \mu \mathrm{m} ; \boldsymbol{G}, 3 \mu \mathrm{m} ; \boldsymbol{H}, \boldsymbol{I}, 5 \mu \mathrm{m}$. Unpaired Student's $t$ test was used to determine significance of $\delta \boldsymbol{C}_{\mathrm{t}}$ values. ${ }^{* * * *} p<0.0001 .{ }^{* *} p<0.01$. Movie 4 is of $\boldsymbol{C}, \boldsymbol{F}$. Movie 3 is of $\boldsymbol{D}, \boldsymbol{G}$. Movie 1 is of $\boldsymbol{H}$. Movie 2 is of $\boldsymbol{I}$.

microscopy and IMARIS-based 3D rendering (Fig. 7A-I). While $\mathrm{CC}^{+}$cells were rare, we did observe microglia engulfing $\mathrm{CC}^{+}$ apoptotic cells that were almost always Brn3 ${ }^{-}$(Fig. 7 A, E). More abundantly, however, we found microglia contacting and interacting with Brn $3^{+}$RGCs (Fig. $7 B-D, F-I$ ). Analysis through the $Z$ plane verified microglia ensheathing RGCs and entire Brn $3^{+}$ cells within microglia (Fig. $7 B$ ). Additionally, costaining with $\mathrm{CC}^{+}$revealed that these RGCs were not undergoing CC3mediated apoptosis (Fig. 7C,D,F,G; Movies 3, 4, 5). Microglia formed phagocytic cups (Fig. 7C,F; Movie 4) and also ensheathed entire Brn3 ${ }^{+}$RGCs (Fig. 7 B,D,G-I; Movies 1, 2, 3). We also observed what appeared to be Brn3-labeled fragments inside microglia (Movie 5). Many of these events were occurring right at the interface of the DCL and NbL, suggesting that newly born RGCs were being targeted, consistent with our BrdU analysis (Fig. $5 F$ ).

To further test whether microglia regulate RGC number by engulfment, we assessed microglia gene expression patterns by whole-retina qRT-PCR. We analyzed genes at e12.5 relative to P0, the end of embryonic development when microglia density is comparable and RGC generation is largely complete. We analyzed genes associated with phagocytosis: recognition receptor Tyrosine-protein kinase Mer (Mertk), lysosomal protein Cd68, complement component 1q (C1qb), and complement component 3 (C3). Relative to $\mathrm{P} 0$, all genes were highly upregulated at e12.5 (Fig. 7J; $n=3$ each; Mertk, $p=4.8 \mathrm{E}-05$; Cd68, $p=0.0031$; $\mathrm{C} 1 \mathrm{qb}, p=0.0012$; $\mathrm{C} 3, p=0.0018)$. We confirmed that these gene expression patterns were not due to contamination from peripheral macrophages because we could not amplify the macrophagespecific gene, $C c r 2$, by qPCR at any age (data not shown). We next asked whether the subset of RGCs being eliminated were viable. We depleted microglia as before (Fig. 2) and aged animals until e20.5/P0. If the normally eliminated RGCs were viable, we would predict a sustained increase in RGC density at birth. Consistent with this, $\mathrm{Brn}^{+}$RGC density was increased compared with littermate controls at e20.5/P0 by $\sim 20 \%$ (Fig. $7 K ; n=3$ animals/5 retinas; onesample two-tailed $t$ test $p=0.0023$ ). These data suggest that microglia are contacting and eliminating viable RGCs. 


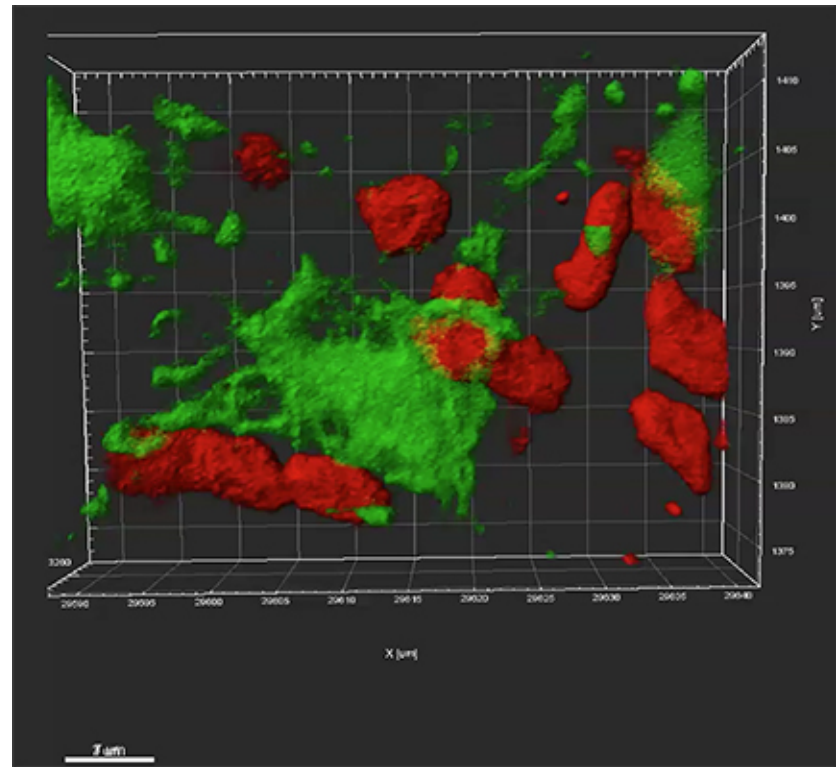

Movie 1. IMARIS 3D rendering of a microglia cell wrapping around an entire RGC in Figure 7H. Green represents Cx3cr1-gfp. Red represents Brn3.

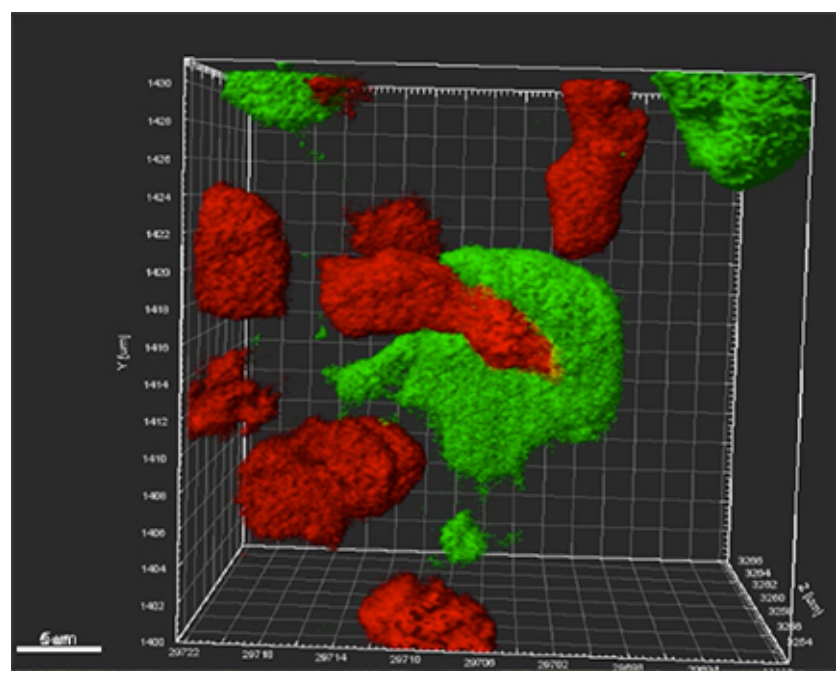

Movie 2. IMARIS 3D rendering of a microglia cell engulfing an entire RGC in Figure 7I. Green represents Cx3cr1-gfp. Red represents Brn3.

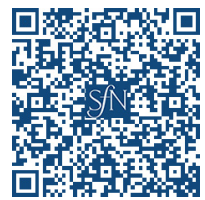

Complement proteins and phagocytosis are reduced following minocycline, and $\mathrm{CR} 3 / \mathrm{Cd} 11 \mathrm{~b} \mathrm{KO}$ retinas have increased RGC density

Minocycline has previously been implicated in reducing phagocytic activity (Schafer et al., 2012). Therefore, we proposed that readouts of phagocytosis would be diminished in minocyclinetreated retinas. We first assessed the lysosomal-associated protein, Cd68, in retinal cross sections of animals given two doses of minocycline or vehicle only once a day at e12.5 and e13.5 and analyzed $2 \mathrm{~h}$ later (Fig. 8A). While there was no significant reduc-

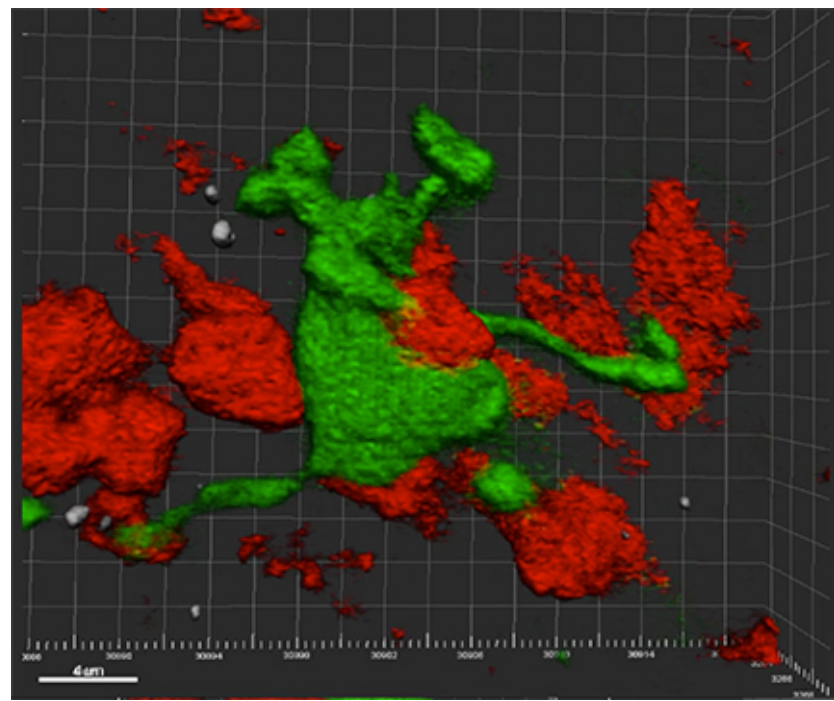

Movie 3. IMARIS 3D rendering of a microglia cell ensheathing a non$\mathrm{CC}^{+} \mathrm{RGC}$ in Figure 7D, G. Green represents Cx3cr1-gfp. White represents CC3. Red represents Brn3.
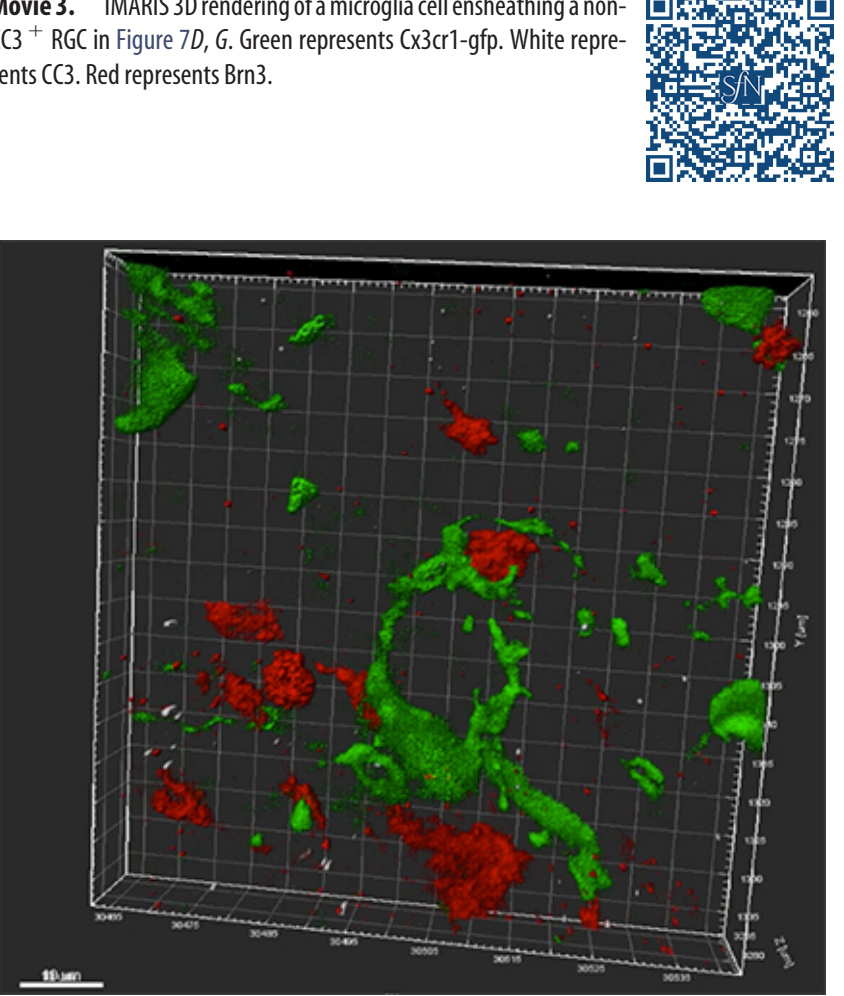

Movie 4. IMARIS 3D rendering of a microglial phagocytic cup around a non-CC ${ }^{+}$RGC in Figure $7 C, F$. Green represents Cx3cr1-gfp. White represents CC3. Red represents Brn3.

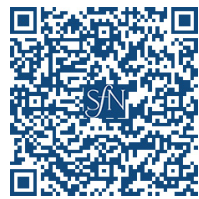

tion in total density of $\mathrm{GFP}^{+}$microglia in treated retinas, the density of microglia with visible lysosomal compartments $\left(\mathrm{GFP}^{+} \mathrm{CD}^{+} 8^{+}\right)$was significantly reduced compared with controls (Fig. $8 B ; n=3$ each; $p=0.044$ ). We then assessed gene expression of candidate phagocytosis genes in e13.5 minocycline and control retinas. We confirmed efficacy of minocycline treatment by a $\sim 38 \%$ reduction in Ibal mRNA (Fig. $8 C$; $n=8$ controls; $n=12$ minocycline-treated; $p=0.0046)$. However, common recognition receptors and associated phagocytosis genes were largely unchanged (Fig. 8C). Mertk, Milk fat globule 


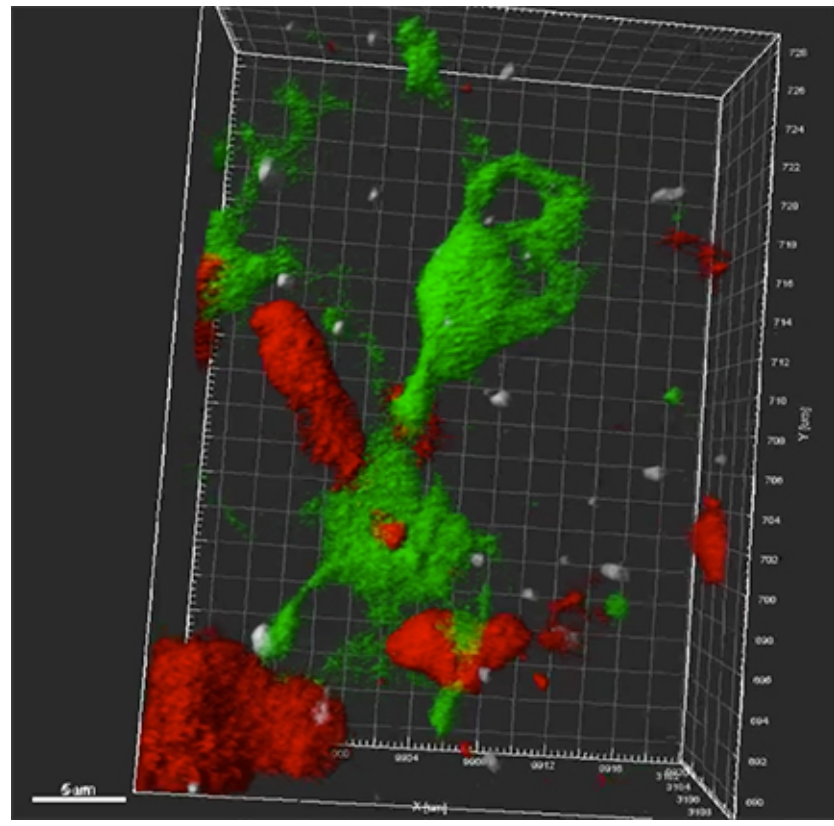

Movie 5. IMARIS 3D rendering of Brn3 protein fragments inside a microglial cell not colocalized with CC3. Green represents Cx3cr1-gfp. White represents $\mathrm{CC}$. Red represents Brn3.

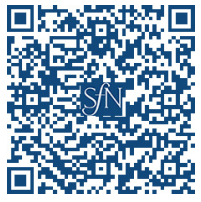

epidermal growth factor 8 (Mfge8), and Itgav of the vitronectin receptor (VNR), which recognize exposed phosphatidylserine, were not significantly altered following minocycline treatment $(n=8$ controls; $n=12$ minocycline-treated; MertK, $p=0.732$; Mfge8, $p=0.516$; VNR, $p=0.144$ ). Tyrobp, which encodes DAP12, a coreceptor previously implicated in the recognition of dying cells (Wakselman et al., 2008), was not significantly downregulated following minocycline treatment $(p=0.197)$. However, Lipoprotein receptor-related protein 1 ( $\operatorname{rrp} 1)$, which can recognize $\mathrm{Clq}$ and exposed Calreticulin on stressed or dying cells, was significantly downregulated with treatment $(p=0.013)$ (Brown and Neher, 2014). Because complement proteins were highly upregulated at e12.5 (Fig. $7 J$ ), we measured expression of Cd11b, a subunit of the CR3 as well as C3 and C1q. Minocycline treatment significantly reduced expression of both Itgam (Cd11b) and $C 3$ but not $C 1 q b$ at e13.5 (Fig. $8 D ; n=8$ controls; 12 minocycline; Itgam $p=0.008 ; \mathrm{C} 3, p=0.011 ; \mathrm{C} 1 \mathrm{qb}, p=0.314)$; however, at e16.5, we also saw a significant reduction in $C 1 q b$ expression (Fig. $8 D ; n=3$ control; $n=10$ minocycline; $p=$ 0.00047). We also analyzed expression of Mertk, VNR, Mfge8, Gas6, Calreticulin, and "don't eat me" signal Cd47 at e16.5 and found that, again, none was altered (data not shown). Thus, of the known recognition receptors and accessory proteins known to be important for microglia phagocytosis, complement components were selectively downregulated with minocycline treatment.

To determine whether complement may be marking RGCs for phagocytic elimination, we assessed protein localization of $\mathrm{Clq}$ by immunostaining. We found that microglia highly express $\mathrm{Clq}$ as expected, but also observed Brn $3^{+}$RGCs were colabeled with $\mathrm{Clq}$ in whole-mount retinas at e13.5 $\left(\mathrm{Brn}^{+} \mathrm{Clq}^{+} \mathrm{GFP}^{-}\right)$(Fig. $8 E)$. Furthermore, we observed contact between $\mathrm{GFP}^{+} \mathrm{Clq}^{+} \mathrm{mi}^{-}$ croglia and $\mathrm{Clq}^{+} \mathrm{Brn}^{+}$RGCs (Fig. 8E1,F). We did find that C1q expression only localized to a subset of RGCs (Fig. 8E2,E3). This was confirmed in retinal cross sections at e16.5, which again showed that a subset of $\mathrm{Brn}^{+}{ }^{+}$RGCs were $\mathrm{Clq}^{+}$(Fig. $8 F$ ). We predominately saw $\mathrm{Clq}^{+} \mathrm{Brn} 3^{+}$RGCs along the edge of the DCL, consistent with our hypothesis that microglia target newly born RGCs. At P0, C1q was deposited in the emerging inner plexiform and nerve fiber layers, but we did not observe $\mathrm{C}_{1 \mathrm{q}}{ }^{+}$ $\mathrm{Brn}^{+}$RGCs, suggesting that RGCs are marked during a narrow developmental window (data not shown). While both microglia and RGCs can produce C1q (Stevens et al., 2007; Fonseca et al., 2017), only microglia express complement receptor 3 (CR3, Cd11b) within the CNS (Jeong et al., 2013). Because Cd11b transcript was diminished (Itgam; Fig. 8D), we next tested whether $\mathrm{Cd} 11 \mathrm{~b}$ protein was also reduced following minocycline treatment. In retinal cross sections at e13.5, we observed a significant reduction in the density of $\mathrm{CD} 11 \mathrm{~b}^{\mathrm{Hi}}$ microglia in minocyclinetreated retinas compared with controls similar to previous work (Schafer et al., 2012) (Fig. 8G,H; $n=3$ each; $p<0.02$ ).

We next directly tested whether complement signaling through CR3 was required for regulation of RGC number. Therefore, we analyzed RGC density in CR3 KOs, with the prediction that RGCs would be increased in the absence of the recognition receptor. Compared with WT littermate controls (CR3 WT), we found P0 CR3 KOs had significantly more Brn $3^{+}$cells per millimeter (Fig. $8 I, K ; n=5$ animals/10 retinas $\mathrm{WT}$ and $n=5$ animals/9 retinas $\mathrm{KO}$; normalized to controls, one-sample twotailed $t$ test, $p=0.006$ ) with no change in microglial density by Iba1 immunofluorescence (Fig. $8 I, J ; n=5$ animals/10 retinas WT and $n=5$ animals/ 9 retinas KO; two sample two-tailed $t$ test, $p=0.122)$. Together, these results suggest that microglia use complement signaling to recognize and eliminate a subset of non-CC3 ${ }^{+}$, newborn RGCs.

\section{Discussion}

The proper development of the CNS, including the retina, requires the appropriate balance of neuron production and elimination to attain the correct number of cell types (Oppenheim, 1991). It is estimated that half of the original cell population in the developing CNS is eventually eliminated (Oppenheim, 1981; Burek and Oppenheim, 1999). Therefore, signals facilitating the delicate balance between cell survival and cell death are indispensable for maintaining tissue homeostasis. The most studied cell elimination processes during development commonly involve apoptotic programs (Jacobson et al., 1997; Yamaguchi and Miura, 2015). Generally, initiation of a cascade of proapoptotic events occurs in one of two ways: self-execution driven by intrinsic programs or extrinsic signals, such as death ligands (Johnson and Deckwerth, 1993). However, there is increasing evidence that there are non-cell-autonomous ways to regulate neuron number that do not require apoptosis.

During retinal development, $\sim 50 \%$ of RGCs produced will undergo developmental death during the first postnatal week (Farah, 2006). Postnatal RGC loss requires apoptosis and is hypothesized to be a result of overproduction of RGCs competing for limited neurotrophic supply and by activity-dependent processes (Perry et al., 1983; Oppenheim, 1991; Péquignot et al., 2003; Farah, 2006). However, most investigations of RGC developmental death neglect prenatal periods, likely because little apoptosis, identified by CC3 and TUNEL, is detected in the DCL prenatally (Young, 1984) and ongoing RGC genesis makes analysis complex. Direct counts of RGC axons in other mammals reveals an embryonic wave of RGC loss (Crespo et al., 1985; Williams et al., 1986), and analysis of RGC somas at individual time points in mouse (Farah and Easter, 2005) predicts a 10\%-15\% loss of RGCs before birth. Here, we find that this embryonic wave 

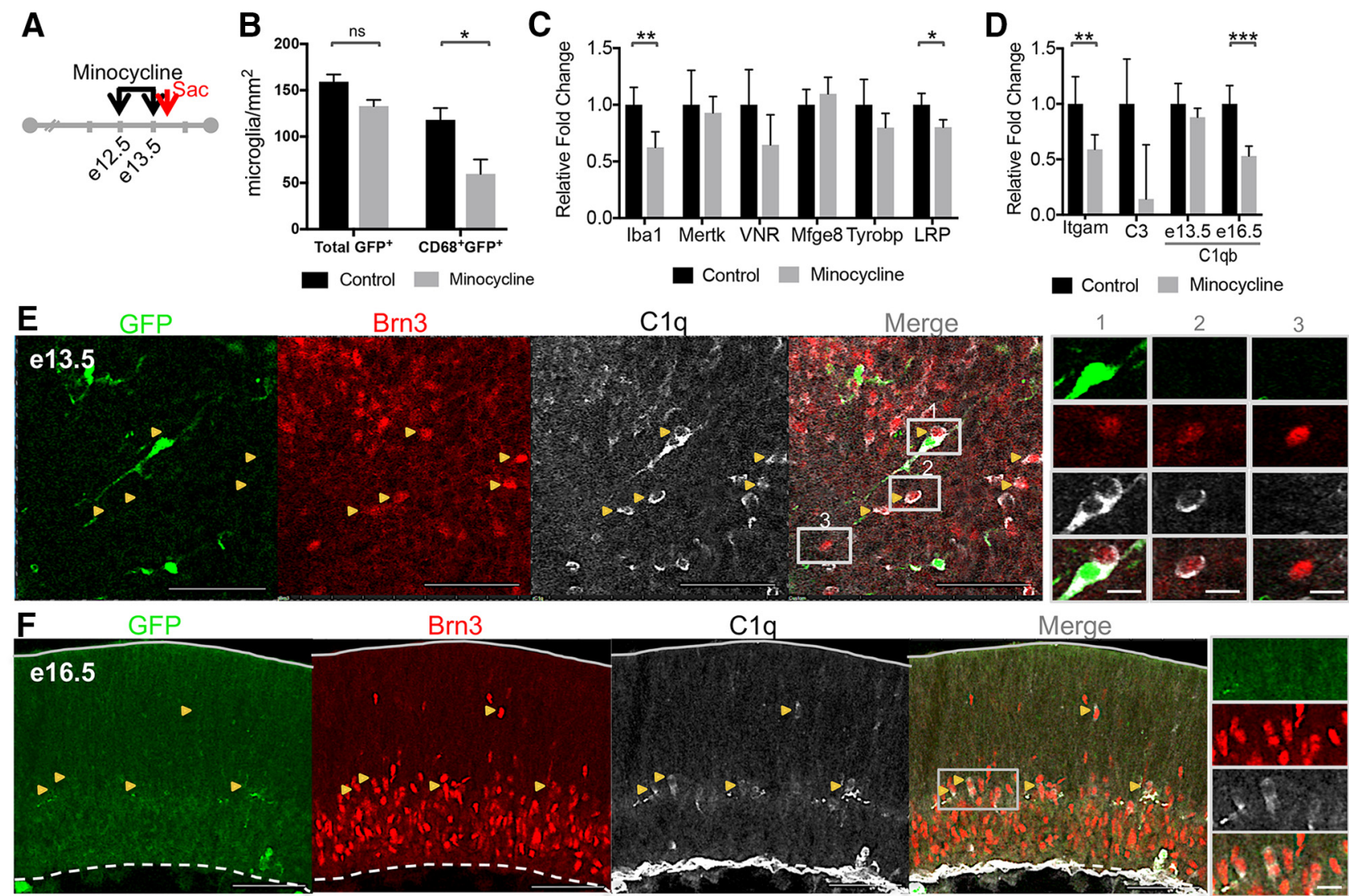

Merge
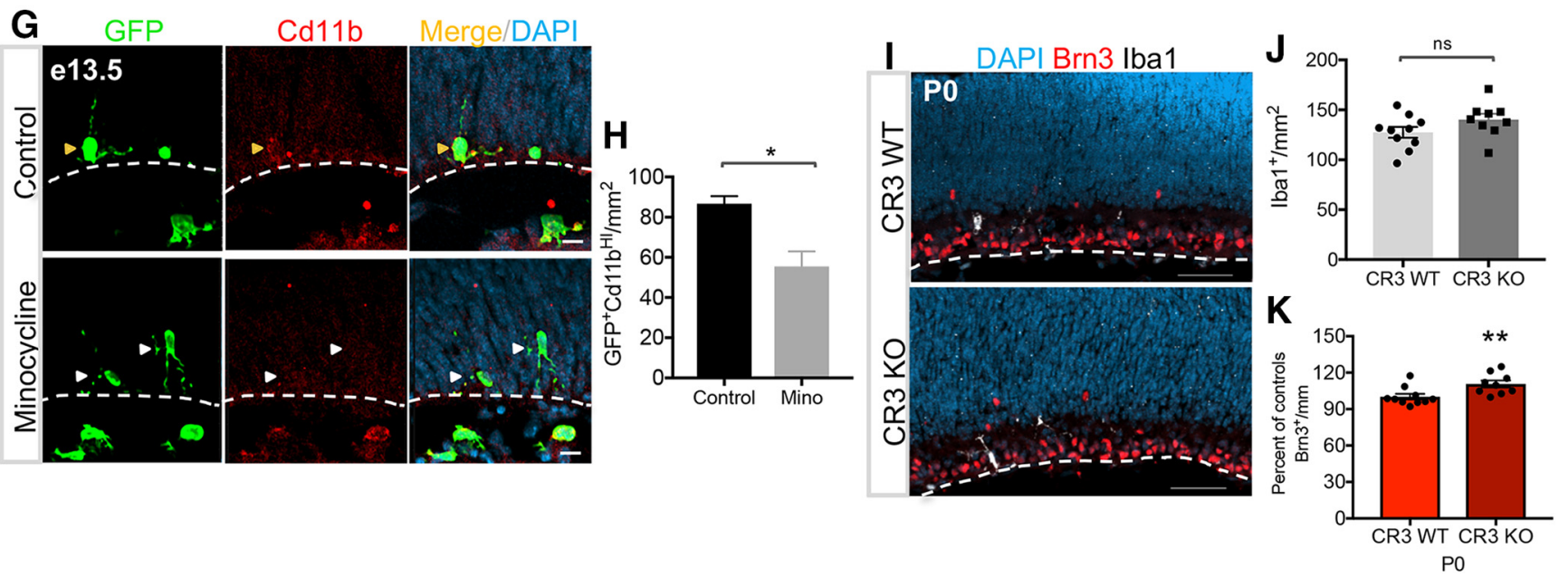

Figure 8. Complement proteins are downregulated with minocycline treatment, and loss of CR3/Cd11b results in increased RGC density. $A$, Minocycline dosing regimen at e12.5 and e13.5 and death $2 \mathrm{~h}$ later. B, Quantification of overall microglial density $\left(\mathrm{GFP}^{+} / \mathrm{mm}^{2}\right)$ and the density of microglia with Cd68 ${ }^{+}$lysosomal compartments $\left(\mathrm{Cd}^{2} 8^{+} \mathrm{GFP}^{+} / \mathrm{mm}^{2}\right)$ in minocycline-treated and

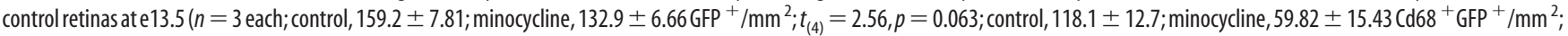
$\left.t_{(4)}=2.913, p=0.044\right)$. C, Whole-retina qRT-PCR of Iba1 and microglial receptors commonly associated with phagocytosis $\left(n \geq 6\right.$ control, $n \geq 11$ minocycline; lba1, $t_{(18)}=3.23, p=0.0046$; Mertk, $t_{(18)}=0.348, p=0.732 ; \mathrm{VNR}, t_{(18)}=1.53, p=0.144 ;$ Mfge8, $t_{(10)}=0.673, p=0.516 ;$ Tyrobp, $t_{(17)}=1.34, p=0.197 ;$ LRP, $\left.t_{(17)}=2.77, p=0.013\right)$. Normalized to $\beta$ actin and relative to age-matched vehicle only controls. $\boldsymbol{D}$, Whole-retina qRT-PCR of complement proteins $\left(n \geq 6\right.$ controls, $n \geq 11$ minocycline-treated; $C \mathrm{~d} 11 \mathrm{~b}, t_{(18)}=2.96, p=0.008 ; C 3, t_{(16)}=1.912, p=0.074$; $\mathrm{e} 13.5, \mathrm{C} 1 \mathrm{qb}, t_{(18)}=1.04, p=0.314 ; \mathrm{e} 16.5, \mathrm{C} 1 \mathrm{qb}, n=3$ controls, 10 treated; $\left.t_{(11)}=4.91, p=0.0005\right)$. Normalized to $\beta$ actin and relative to age-matched vehicle only controls. $E$, e 13.5 retinal

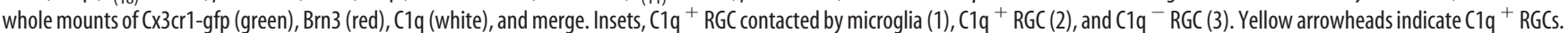
F, e16.5 retinal cross sections of Cx3cr1-gfp (green), Brn3 (red), C1q (white), and merge. Inset, Magnification of C1q ${ }^{+}$RGCs along DCL border. Yellow arrowheads indicate C1q ${ }^{+}$RGCs. G, e13.5 retinal cross sections of Cd11b immunostaining: DAPI (blue), CX3cr1-gfp (green), and Cd11b ${ }^{+}$(red). Yellow arrowheads indicate $\left(\mathrm{d} 11 \mathrm{~b}^{\mathrm{HI}}\right.$ microglia. White arrowheads indicate $\mathrm{Cd} 11 \mathrm{~b}{ }^{\mathrm{L}}{ }^{\mathrm{O}}$ microglia. $\boldsymbol{H}$, Quantification of microglia highly expressing (d11b (GFP ${ }^{+} \mathrm{Cd}_{\left.11 \mathrm{~b}^{\mathrm{Hi}}\right)}$ at e13.5 ( $n=3$ each; control, $86.73 \pm 3.71$, minocycline, $\left.55.45 \pm 7.48 ; t_{(4)}=3.75, p=0.02\right) . \boldsymbol{I}$, Retinal cross sections of e16.5 control (CR3 WT) and complement receptor (CR3) K0 animals: Iba1 (green) and Brn3 (red).J, Analysis of microglial density (lba1/mm $\left.{ }^{2}\right)$ in CR3 K0 and littermate WT controls ( $n=5$ animals $/ 10$ retinas WT, $127.4 \pm 5.42 ; n=5$ animals/9 retinas $\mathrm{KO}, 140.3 \pm 5.74$; two-sample $t$ test $\left.t_{(17)}=1.626, p=0.122\right) . \boldsymbol{K}$, Analysis of RGC density in CR3 K0 and controls. Data were normalized to littermate controls because 3 litters were used ( $n=5$ animals/ 10 retinas WT, $n=5$ animals/9 retinas K0; one-sample $t$ test $t_{(8)}=3.71, p=0.006$ ). Scale bars: $50 \mu \mathrm{m}$ for retinal whole mounts and central regions of retinal cross sections, $10 \mu \mathrm{m}$ for higher-magnification insets, and in $\mathbf{G}$. C, D, qPCR graphs represent fold change. Error bar indicates the SEM of $\delta C_{\mathrm{t}}$ values. Graphs represent mean \pm h SEM. ${ }^{* * *} p<0.001 .{ }^{* *} p<0.01 .{ }^{*} p<0.05$. 
of RGC loss requires microglial presence and function with no change in caspase-dependent apoptosis programs.

Microglia can eliminate neurons in a matter of hours (Neher et al., 2011; Zhao et al., 2015), making phagocytic events hard to detect at static time points ex vivo. Nevertheless, increasing evidence suggests that phagocytosis is a highly regulated, complex process with functions beyond passive clearance of dying cells or cellular debris. The active elimination of stressed, but viable, cells has been dubbed phagoptosis, or primary phagocytosis, and events are well documented in culture (Brown and Neher, 2012, 2014; Vilalta and Brown, 2018). There is also evidence in vivo both during development and disease that microglia can eliminate nonapoptotic cells. During cortical development, microglia engulf viable neural progenitors to limit the number of neurons generated (Cunningham et al., 2013). Microglia contribute to retinal degeneration by the phagocytosis of living but stressed photoreceptors in Rd10 mutants (Zhao et al., 2015). Additionally, microglia phagocytose viable neurons during transient cerebral ischemia (Neher et al., 2013; Alawieh et al., 2018) and adult newborn dentate granule cells in a mouse model of temporal lobe epilepsy (Luo et al., 2016). We provide evidence that microglia also actively select a subpopulation of seemingly viable RGCs to be eliminated in the developing retina. It remains possible that microglia secrete factors to stimulate non-CC3-dependent death. However, we find microglial phagocytosis is high during relevant time periods, is regulated with minocycline treatment, and microglia frequently interact with and ensheath nonapoptotic RGCs. Because RGC density in microglia depleted retinas remains increased at birth, this suggests that these RGCs are viable and normally eliminated by phagocytosis.

To date, the molecular mechanisms driving phagoptosis in vivo are largely unknown. However, there is evidence that Mertk and Mfges (Neher et al., 2013) are involved in engulfment of stressed neurons following ischemia. In a model of ischemic stroke, targeted inhibition of complement or $\mathrm{KO}$ of $\mathrm{C} 3$ limits microglial contact and engulfment of stressed, noncleaved caspase $3^{+}$neurons (Alawieh et al., 2018). Here, we find that complement proteins are an important signal for RGC removal by microglia. The complement system has been implicated in development and disease with a primary focus on the ability of complement to tag synapses for pruning (Stevens et al., 2007; Schafer et al., 2012; Stephan et al., 2012; Zabel and Kirsch, 2013; Hong et al., 2016; Coulthard et al., 2018; Hawksworth et al., 2018). Complement is important for RGC-microglia interactions during postnatal periods by marking RGC synapses in the LGN for microglial engulfment (Schafer et al., 2012). We show that complement signaling via CR3 is required for normal elimination of RGCs embryonically because an excess of RGCs was present at $\mathrm{P} 0$ in the CR3 KO retina. It is likely other phagocytosis pathways also contribute because we see less of an increase in RGC density in CR3 KO retinas than is observed following microglial depletion. These findings are consistent with previous work, where loss of complement receptor signaling did not completely abolish phagocytosis but reduced engulfment by $\sim 50 \%$ (Schafer et al., 2012). One interesting candidate that may participate in RGC elimination is LRP because we observed a significant downregulation of its expression with minocycline treatment and LRP can recognize Clq to stimulate phagocytosis (Brown and Neher, 2014). These findings represent some of the first evidence that complement signaling can stimulate engulfment of entire neurons in vivo. This has major ramifications not only during development but also in pathological states.
Complement is upregulated early and implicated in driving pathology in various contexts of injury and neurodegeneration (Bonifati and Kishore, 2007; Zabel and Kirsch, 2013), including glaucoma, which is the progressive decline and loss of RGCs (Soto and Howell, 2014; Williams et al., 2017). During glaucoma progression, complement proteins, such as $\mathrm{Clq}$, become localized to RGC synapses and cell bodies (Stevens et al., 2007). Therefore, it is an intriguing possibility that the developmental microglia-RGC interactions found here may reemerge in glaucoma.

We found that microglia were regulating RGC number embryonically, with no apparent effect on cones or amacrine cells, although effects on other cell types cannot be ruled out. Why a subset of seemingly viable RGCs would be eliminated during peak RGC genesis is unknown. Because RGC density is tightly regulated (Wang et al., 2005) and various "don't eat me" signals limit aberrant phagocytosis (Elward and Gasque, 2003), it is unlikely that microglia target RGCs stochastically. An alternative hypothesis is that microglia target specific RGCs that may be less fit for their environment. Many factors can influence whether a newborn neuron will live or die during development, including sufficient neurotrophic support, proper migration, correct timing, cell-cell interactions, successful axon guidance and innervation, and sufficient neuronal activity (Yamaguchi and Miura, 2015). Cell competition can also drive elimination of viable, but less fit, cells during development (Gogna et al., 2015). A few reports have illustrated the ability of microglia to "sense" and eliminate neurons displaying cellular dysfunction and stress (Brown and Neher, 2012, 2014; Zhao et al., 2015). Therefore, it is possible that microglia eliminate stressed RGCs before they become a liability or less fit RGCs competing for limited space and resources. Our RGC labeling analysis with BrdU suggests that RGCs are primarily being targeted at least $24 \mathrm{~h}$ after birth. While this provides clues as to what could be driving their elimination, various possibilities remain. RGC axons reach the optic nerve 24-48 h after birth (Farah and Easter, 2005), suggesting that axon guidance mishaps could drive RGC elimination. Because both minocycline treatment and genetic depletion of microglia are systemic, it is possible that microglia may have important roles at other RGC compartments, including RGC targets in the brain, such as the superior colliculus or lateral geniculate nucleus. Interestingly, complement components are important for the proper migration of both neural crest cells and cortical neurons (Coulthard et al., 2018). Therefore, it is also plausible that targeted RGCs have improperly migrated. Because we identify Clqpositive RGCs along the edge of the DCL where migrating RGCs arrive, and we observe many microglia-RGC contact events, it is intriguing to speculate that there is a checkpoint for newborn RGCs. If true, this process may be another level of refinement important for CNS development and function.

Currently, it is unclear whether the addition of these normally eliminated RGCs has any long-term effects. By P6, we find a slight, but insignificant, increase in Brn3 density in minocyclinetreated retinas (data not shown), suggesting that Brn3 density normalizes and excess neurons may be eliminated during postnatal apoptosis-mediated refinement (Farah, 2006).

While proper CNS development necessitates appropriate production of cell types, the successful elimination of a fixed proportion is essential for homeostasis and CNS refinement (Oppenheim, 1991). Here, we provide evidence for a novel mechanism of neuron elimination in the developing retina, whereby microglia directly limit seemingly viable RGCs by phagocytosis. We find this is partially dependent on complement signaling, which exposes an ancillary role for this ancient signaling system. 
In addition, we uncover an avenue of microglia-neuron crosstalk that could have major implications during CNS development but also in complex contexts of injury and disease.

\section{References}

Alawieh A, Langley EF, Tomlinson S (2018) Targeted complement inhibition salvages stressed neurons and inhibits neuroinflammation after stroke in mice. Sci Transl Med 10:eaao6459.

Bassett EA, Wallace VA (2012) Cell fate determination in the vertebrate retina. Trends Neurosci 35:565-573.

Bilimoria PM, Stevens B (2015) Microglia function during brain development: new insights from animal models. Brain Res 1617:7-17.

Bonifati DM, Kishore U (2007) Role of complement in neurodegeneration and neuroinflammation. Mol Immunol 44:999-1010.

Bosco A, Inman DM, Steele MR, Wu G, Soto I, Marsh-Armstrong N, Hubbard WC, Calkins DJ, Horner PJ, Vetter ML (2008) Reduced retina microglial activation and improved optic nerve integrity with minocycline treatment in the DBA/2J mouse model of glaucoma. Invest Ophthalmol Vis Sci 49:1437-1446.

Brown GC, Neher JJ (2012) Eaten alive! Cell death by primary phagocytosis: 'phagoptosis.' Trends Biochem Sci 37:325-332.

Brown GC, Neher JJ (2014) Microglial phagocytosis of live neurons. Nat Rev Neurosci 15:209-216.

Burek MJ, Oppenheim RW (1999) Cellular interactions that regulate programmed cell death in the developing vertebrate nervous system. In: Cell death and diseases of the nervous system (Koliatsos VE, Ratan RR, eds), pp 145-179. Totowa, NJ: Humana.

Casano AM, Albert M, Peri F (2016) Developmental apoptosis mediates entry and positioning of microglia in the zebrafish brain. Cell Rep 16:897906.

Chen SK, Chew KS, McNeill DS, Keeley PW, Ecker JL, Mao BQ, Pahlberg J, Kim B, Lee SC, Fox MA, Guido W, Wong KY, Sampath AP, Reese BE, Kuruvilla R, Hattar S (2013) Apoptosis regulates ipRGC spacing necessary for rods and cones to drive circadian photoentrainment. Neuron 77:503-515.

Chitu V, Gokhan S, Nandi S, Mehler MF, Stanley ER (2016) Emerging roles for CSF-1 receptor and its ligands in the nervous system. Trends Neurosci 39:378-393.

Coulthard LG, Hawksworth OA, Woodruff TM (2018) Complement: the emerging architect of the developing brain. Trends Neurosci 41:373-384.

Coxon A, Rieu P, Barkalow FJ, Askari S, Sharpe AH, von Andrian UH, Arnaout MA, Mayadas TN (1996) A novel role for the $\beta 2$ integrin CD11b/ CD18 in neutrophil apoptosis: a homeostatic mechanism in inflammation. Immunity 5:653-666.

Crespo D, O'Leary DD, Maxwell CW (1985) Changes in the numbers of optic nerve fibers during late prenatal and postnatal development in the albino rat. Dev Brain Res 19:129-134.

Cunningham CL, Martínez-Cerdeño V, Noctor SC (2013) Microglia regulate the number of neural precursor cells in the developing cerebral cortex. J Neurosci 33:4216-4233.

Ekdahl CT, Kokaia Z, Lindvall O (2009) Brain inflammation and adult neurogenesis: the dual role of microglia. Neuroscience 158:1021-1029.

Elmore MR, Najafi AR, Koike MA, Dagher NN, Spangenberg EE, Rice RA, Kitazawa M, Matusow B, Nguyen H, West BL, Green KN (2014) Colony-stimulating factor 1 receptor signaling is necessary for microglia viability, unmasking a microglia progenitor cell in the adult brain. Neuron 82:380-397.

Elmore MR, Lee RJ, West BL, Green KN (2015) Characterizing newly repopulated microglia in the adult mouse: impacts on animal behavior, cell morphology, and neuroinflammation. PLoS One 10:e0122912.

Elward K, Gasque P (2003) "Eat me" and "don't eat me" signals govern the innate immune response and tissue repair in the CNS: emphasis on the critical role of the complement system. Mol Immunol 40:85-94.

Erblich B, Zhu L, Etgen AM, Dobrenis K, Pollard JW (2011) Absence of colony stimulation factor- 1 receptor results in loss of microglia, disrupted brain development and olfactory deficits. PLoS One 6:e26317.

Farah MH (2006) Neurogenesis and cell death in the ganglion cell layer of vertebrate retina. Brain Res Rev 52:264-274.

Farah MH, Easter SS Jr (2005) Cell birth and death in the mouse retinal ganglion cell layer. J Comp Neurol 489:120-134.

Fonseca MI, Chu SH, Hernandez MX, Fang MJ, Modarresi L, Selvan P, MacGregor GR, Tenner AJ (2017) Cell-specific deletion of C1qa identi- fies microglia as the dominant source of C1q in mouse brain. J Neuroinflammation 14:48.

Fourgeaud L, Través PG, Tufail Y, Leal-Bailey H, Lew ED, Burrola PG, Callaway P, Zagórska A, Rothlin CV, Nimmerjahn A, Lemke G (2016) TAM receptors regulate multiple features of microglial physiology. Nature 532:240-244.

Francisco-Morcillo J, Bejarano-Escobar R, Rodríguez-León J, Navascués J, Martín-Partido G (2014) Ontogenetic cell death and phagocytosis in the visual system of vertebrates. Dev Dyn 243:1203-1225.

Ginhoux F, Lim S, Hoeffel G, Low D, Huber T (2013) Origin and differentiation of microglia. Front Cell Neurosci 7:45.

Gogna R, Shee K, Moreno E (2015) Cell competition during growth and regeneration. Annu Rev Genet 49:697-718.

Hawksworth OA, Coulthard LG, Mantovani S, Woodruff TM (2018) Complement in stem cells and development. Semin Immunol 37:74-84.

Hilla AM, Diekmann H, Fischer D (2017) Microglia are irrelevant for neuronal degeneration and axon regeneration after acute injury. J Neurosci 37:6113-6124.

Hong S, Beja-Glasser VF, Nfonoyim BM, Frouin A, Li S, Ramakrishnan S, Merry KM, Shi Q, Rosenthal A, Barres BA, Lemere CA, Selkoe DJ, Stevens B (2016) Complement and microglia mediate early synapse loss in Alzheimer mouse models. Science 352:712-716.

Huang Y, Xu Z, Xiong S, Qin G, Sun F, Yang J, Yuan TF, Zhao L, Wang K, Liang YX, Fu L, Wu T, So KF, Rao Y, Peng B (2018a) Dual extra-retinal origins of microglia in the model of retinal microglia repopulation. Cell Discov 4:9.

Huang Y, Xu Z, Xiong S, Sun F, Qin G, Hu G, Wang J, Zhao L, Liang YX, Wu T, Lu Z, Humayun MS, So KF, Pan Y, Li N, Yuan TF, Rao Y, Peng B (2018b) Repopulated microglia are solely derived from the proliferation of residual microglia after acute depletion. Nat Neurosci 21:530-540.

Jacobson MD, Weil M, Raff MC (1997) Programmed cell death in animal development. Cell 88:347-354.

Jeong HK, Ji K, Min K, Joe EH (2013) Brain inflammation and microglia: facts and misconceptions. Exp Neurobiol 22:59-67.

Johnson EM Jr, Deckwerth TL (1993) Molecular mechanisms of developmental neuronal death. Annu Rev Neurosci 16:31-46.

Jung S, Aliberti J, Graemmel P, Sunshine MJ, Kreutzberg GW, Sher A, Littman DR (2000) Analysis of fractalkine receptor CX3CR1 function by targeted deletion and green fluorescent protein reporter gene insertion. Mol Cell Biol 20:4106-4114.

Kobayashi K, Imagama S, Ohgomori T, Hirano K, Uchimura K, Sakamoto K, Hirakawa A, Takeuchi H, Suzumura A, Ishiguro N, Kadomatsu K (2013) Minocycline selectively inhibits M1 polarization of microglia. Cell Death Dis 4:e525.

Li J, Chen K, Zhu L, Pollard JW (2006) Conditional deletion of the colony stimulating factor-1 receptor (c-fms proto-oncogene) in mice. Genesis 44:328-335.

Li Q, Barres BA (2018) Microglia and macrophages in brain homeostasis and disease. Nat Rev Immunol 18:225-242.

Luo C, Koyama R, Ikegaya Y (2016) Microglia engulf viable newborn cells in the epileptic dentate gyrus. Glia 64:1508-1517.

Madisen L, Zwingman TA, Sunkin SM, Oh SW, Zariwala HA, Gu H, Ng LL, Palmiter RD, Hawrylycz MJ, Jones AR, Lein ES, Zeng H (2010) A robust and high-throughput Cre reporting and characterization system for the whole mouse brain. Nat Neurosci 13:133-140.

Nandi S, Gokhan S, Dai XM, Wei S, Enikolopov G, Lin H, Mehler MF, Stanley ER (2012) The CSF-1 receptor ligands IL-34 and CSF-1 exhibit distinct developmental brain expression patterns and regulate neural progenitor cell maintenance and maturation. Dev Biol 367:100-113.

Nayak D, Roth TL, McGavern DB (2014) Microglia development and function. Annu Rev Immunol 32:367-402.

Neher JJ, Neniskyte U, Zhao JW, Bal-Price A, Tolkovsky AM, Brown GC (2011) Inhibition of microglial phagocytosis is sufficient to prevent inflammatory neuronal death. J Immunol 186:4973-4983.

Neher JJ, Emmrich JV, Fricker M, Mander PK, Théry C, Brown GC (2013) Phagocytosis executes delayed neuronal death after focal brain ischemia. Proc Natl Acad Sci U S A 110:E4098-E4107.

Oppenheim RW (1981) Cell death of motoneurons in the chick embryo spinal cord: V. Evidence on the role of cell death and neuromuscular function in the formation of specific peripheral connections. J Neurosci 1:141-151. 
Oppenheim RW (1991) Cell death during development of the nervous system. Annu Rev Neurosci 14:453-501.

Péquignot MO, Provost AC, Sallé S, Taupin P, Sainton KM, Marchant D, Martinou JC, Ameisen JC, Jais JP, Abitbol M (2003) Major role of BAX in apoptosis during retinal development and in establishment of a functional postnatal retina. Dev Dyn 228:231-238.

Perry VH, Henderson Z, Linden R (1983) Postnatal changes in retinal ganglion cell and optic axon populations in the pigmented rat. J Comp Neurol 219:356-368.

Ravichandran KS (2010) Find-me and eat-me signals in apoptotic cell clearance: progress and conundrums. J Exp Med 207:1807-1817.

Ricklin D, Hajishengallis G, Yang K, Lambris JD (2010) Complement: a key system for immune surveillance and homeostasis. Nat Immunol 11:785-797.

Santos AM, Calvente R, Tassi M, Carrasco MC, Martín-Oliva D, Marín-Teva JL, Navascués J, Cuadros MA (2008) Embryonic and postnatal development of microglial cells in the mouse retina. J Comp Neurol 506:224-239.

Sato K (2015) Effects of microglia on neurogenesis. Glia 63:1394-1405.

Schafer DP, Lehrman EK, Kautzman AG, Koyama R, Mardinly AR, Yamasaki R, Ransohoff RM, Greenberg ME, Barres BA, Stevens B (2012) Microglia sculpt postnatal neural circuits in an activity and complementdependent manner. Neuron 74:691-705.

Shigemoto-Mogami Y, Hoshikawa K, Goldman JE, Sekino Y, Sato K (2014) Microglia enhance neurogenesis and oligodendrogenesis in the early postnatal subventricular zone. J Neurosci 34:2231-2243.

Sidman RL (1961) Histogenesis of mouse retina studied with thymidineH3, pp 487-506. San Diego: Academic.

Soto I, Howell GR (2014) The complex role of neuroinflammation in glaucoma. Cold Spring Harb Perspect Med 4:a017269.

Stephan AH, Barres BA, Stevens B (2012) The complement system: an unexpected role in synaptic pruning during development and disease. Annu Rev Neurosci 35:369-389.

Stevens B, Allen NJ, Vazquez LE, Howell GR, Christopherson KS, Nouri N, Micheva KD, Mehalow AK, Huberman AD, Stafford B, Sher A, Litke AM, Lambris JD, Smith SJ, John SW, Barres BA (2007) The classical complement cascade mediates CNS synapse elimination. Cell 131:1164-1178.

Ueno M, Fujita Y, Tanaka T, Nakamura Y, Kikuta J, Ishii M, Yamashita T (2013) Layer V cortical neurons require microglial support for survival during postnatal development. Nat Neurosci 16:543-551.
Vilalta A, Brown GC (2018) Neurophagy, the phagocytosis of live neurons and synapses by glia, contributes to brain development and disease. FEBS J 285:3566-3575.

Wakselman S, Béchade C, Roumier A, Bernard D, Triller A, Bessis A (2008) Developmental neuronal death in hippocampus requires the microglial CD11b integrin and DAP12 immunoreceptor. J Neurosci 28:8138-8143.

Wang X, Zhao L, Zhang J, Fariss RN, Ma W, Kretschmer F, Wang M, Qian HH, Badea TC, Diamond JS, Gan WB, Roger JE, Wong WT (2016) Requirement for microglia for the maintenance of synaptic function and integrity in the mature retina. J Neurosci 36:2827-2842.

Wang Y, Dakubo GD, Thurig S, Mazerolle CJ, Wallace VA (2005) Retinal ganglion cell-derived sonic hedgehog locally controls proliferation and the timing of RGC development in the embryonic mouse retina. Development 132:5103-5113.

Williams PA, Marsh-Armstrong N, Howell GR (2017) Neuroinflammation in glaucoma: a new opportunity. Exp Eye Res 157:20-27.

Williams RW, Bastiani MJ, Lia B, Chalupa LM (1986) Growth cones, dying axons, and developmental fluctuations in the fiber population of the cat's optic nerve. J Comp Neurol 246:32-69.

Xu J, Wang T, Wu Y, Jin W, Wen Z (2016) Microglia colonization of developing zebrafish midbrain is promoted by apoptotic neuron and lysophosphatidylcholine. Dev Cell 38:214-222.

Yamaguchi Y, Miura M (2015) Programmed cell death in neurodevelopment. Dev Cell 32:478-490.

Yona S, Kim KW, Wolf Y, Mildner A, Varol D, Breker M, Strauss-Ayali D, Viukov S, Guilliams M, Misharin A, Hume DA, Perlman H, Malissen B, Zelzer E, Jung S (2013) Fate mapping reveals origins and dynamics of monocytes and tissue macrophages under homeostasis. Immunity 38:79-91.

Young RW (1984) Cell death during differentiation of the retina in the mouse. J Comp Neurol 229:362-373.

Zabel MK, Kirsch WM (2013) From development to dysfunction: microglia and the complement cascade in CNS homeostasis. Ageing Res Rev 12:749-756.

Zhao L, Zabel MK, Wang X, Ma W, Shah P, Fariss RN, Qian H, Parkhurst CN, Gan WB, Wong WT (2015) Microglial phagocytosis of living photoreceptors contributes to inherited retinal degeneration. EMBO Mol Med 7:1179-1197. 